\title{
VARIAÇÃO DA ESTRUTURA HORIZONTAL DE COBERTURA VEGETAL NA ÁREA URBANA DE SANTA MARIA (RS) ENTRE 1980 e 2011
}

\author{
Daniel Borini Aves ${ }^{1}$, Adriano Severo Figueiró ${ }^{3}$
}

\section{RESUMO}

O presente artigo objetiva analisar a variação da estrutura horizontal da cobertura vegetal na área urbana de Santa Maria (RS), por meio do mapeamento e mensuração da dinâmica distributiva de vegetação na cidade nas últimas décadas. A análise foi feita com base em um levantamento aerofotogramétrico de janeiro de 1980, composto por um mosaico de 173 fotografias aéreas, e fragmentos da imagem Geoeye, de alta resolução espacial, de 21/09/2011, extraída do software Google Earth 6.1. Os materiais foram georreferenciados e processados junto ao software Spring 5.1.7, que permitiu a geração dos mapeamentos, analisados considerando a variação da cobertura vegetal nas unidades de bairros e Regiões Administrativas atuais da cidade. De forma geral, observa-se uma perda de 12,38\% da cobertura vegetal total da cidade nesses 31 anos, onde se contabilizaram perdas de 4,6\% da vegetação arbórea. Em algumas áreas, como na Região Administrativa Centro Urbano, os bairros perderam cerca de $20 \%$ de cobertura vegetal total, sendo aproximadamente 15\% de perdas de cobertura vegetal arbórea. Acredita-se que a compreensão desses processos permite identificar as áreas onde as perdas de cobertura vegetal na cidade ocorreram com maior intensidade, o que possibilita o estabelecimento de diretrizes de gestão que auxiliem na elaboração de um planejamento urbano e ambiental que considere uma melhor distribuição dos espaços verdes e suas funcionalidades.

Palavras-chave: Paisagem urbana; vegetação; gestão ambiental; urbanização.

\section{VARIATION ON HORIZONTAL STRUCTURE OF VEGETATION COVER IN URBAN AREA OF SANTA MARIA (RS) BETWEEN 1980 AND 2011}

\begin{abstract}
This article aims to analyze the variation of horizontal vegetation structure in the urban area of Santa Maria (RS), based on the mapping and measurement of distributive dynamics of vegetation in the city in recent decades. The analysis was based on a survey aero photogrammetric of January 1980, consisting of a mosaic of 173 aerial photographs, and Geoeye image fragments, high spatial resolution, of 09/21/2011, extracted from the software Google Earth 6.1. The materials were georeferenced and processed by the Spring 5.1 .7 software, which allowed to mapping production and analysis based on the variation of vegetation units of current administrative regions and districts of the city. Generally, we observed loss of $12.38 \%$ of the city's total vegetation cover towards the last 31 years, which performed in $4.6 \%$ of tree cover losses in the city. In some areas, as in the administrative region Centro Urbano, the districts lost about $20 \%$ of vegetation cover total, being approximately $15 \%$ loss of tree cover. It is believed that understanding these processes allows one to identify the areas where vegetation losses were increased and, also, to promote management guidelines that assist urban and environmental planning considering a better distribution of green spaces and their functionality.
\end{abstract}

Key-words: Urban landscape, vegetation, environmental management, urbanization.

\footnotetext{
${ }^{1}$ Mestre em Geografia (UFSM), doutorando do curso de Ordenación del Territorio y Medio Ambiente na Universidad de Zaragoza (Bolsista CAPES), Calle Pedro Cerbuna, 12, Zaragoza (ES), danielborini.geo@gmail.com

${ }^{2}$ Doutor em Geografia (UFRJ), professor do Departamento Geociências da UFSM, Av. Roraima, prédio 17, sala 1113A, Santa Maria (RS), adri.geo.ufsm@gmail.com

3 recebido em 26.10.2012 e aceito para publicação em 15.03.2014
} 
A intensificação do processo de urbanização é um fenômeno marcante do século XX, que afirma a cidade como a principal morada dos seres humanos. Observados os índices crescentes de população urbana, é um desafio aos pesquisadores e profissionais que discutem o planejamento urbano e ambiental, buscar alternativas que auxiliem na gestão dos conflitos existentes na relação sociedade-natureza dentro destas áreas, garantindo condições de bem viver da população humana sem comprometer a condições naturais, além de considerar os processos ecológicos para um melhor aproveitamento dos benefícios por eles proporcionados (DIAS, 1997).

A paisagem urbana, ao refletir o convívio direto e mediado do homem junto à natureza, é o espaço onde os conflitos ambientais se demonstram mais agravados e aparentes, o que evidencia a realidade acerca da deterioração das relações dos indivíduos em sociedade junto ao meio natural. Ao serem compreendidas como sistemas, onde se manifestam fluxos dinâmicos de energia, matéria e informação, as cidades passam a se diferenciar do seu entorno rural, sofrendo muitas vezes com a excessiva artificialização de sua estrutura, que tem como consequências a perda de funcionalidades ambientais.

Na perspectiva da consideração dos atributos naturais no planejamento urbano, acredita-se que quando se fala em planejar com a natureza, dentro da linha metodológica do planejamento da paisagem, se está falando, principalmente, do manejo adequado da vegetação, sendo a partir dela que muitos problemas podem ser amenizados ou resolvidos (NUCCI, 2008). Assim, a cobertura vegetal, tanto em termos qualitativo como quantitativo e, também, a sua distribuição espacial, deve ser cuidadosamente considerada na avaliação da qualidade ambiental (TIAN et al., 2014; PHAM et al., 2012).

Diante deste contexto, o presente trabalho busca analisar a variação da estrutura horizontal da cobertura vegetal na área urbana de Santa Maria (RS), por meio do mapeamento e mensuração da distribuição da vegetação na cidade nas últimas décadas (1980-2011). Acredita-se que a compreensão dessa estrutura é fundamental para identificar as áreas aonde as perdas de cobertura vegetal - e, por conseguinte, de funcionalidades ambientais - tem se dado de forma mais intensa. Uma vez identificadas, estas áreas podem ser tratadas como prioritárias na construção de estratégias de recuperação das funcionalidades ambientais urbanas dentro de um processo de gestão ambiental que considere uma melhor distribuição dos espaços verdes e os serviços ambientais a eles associados, tais como regulação térmica, retenção de água, manutenção da umidade, retenção de poeiras e possibilidades de lazer.

\section{O processo de urbanização e a contribuição da cobertura vegetal}

Ao discutir-se a dinâmica da paisagem urbana em relação ao crescimento das cidades a partir do processo de apropriação do espaço, observa-se que a impermeabilização dos lotes e a consequente diminuição da cobertura vegetal em áreas urbanas é um dos fatores mais perceptíveis nestes ambientes, e que representam a diminuição de uma série de funcionalidades ambientais das quais a vegetação é, em parte significativa, responsável (ALBERTI, 1999; SPIRN, 1995).

Ao apontar a insuficiência ou inadequação das medidas tecnológicas para o controle das degradações

Daniel Borini Aves e Adriano Severo Figueiró 
ambientais, Cavalheiro (2009) discute que parece mais lógico que, primeiramente, se tire proveito do que a natureza pode oferecer no tocante à auto-regulação, para então estudar quais devem ser as tecnologias mais compatíveis a serem utilizadas.

Acredita-se que o processo de ordenamento e regulação das atividades urbanas deve conter estratégias adaptadas a cada local para a manutenção ecológica, permeabilidade de solos, regulação da temperatura, abrigo e produção de alimentos para determinadas espécies, com a finalidade de ultrapassar a concepção simplista de se considerar a paisagem exclusivamente a partir do seu caráter estético, tal como ainda o fazem muitos gestores municipais de meio ambiente (BORGES et al., 2010).

Nucci (2008) destaca o papel da cobertura vegetal na qualidade ambiental urbana, ao identificá-la como um atributo muito importante, porém negligenciado, no desenvolvimento das cidades, visto que, diferentemente da terra, do ar e da água, não se demonstra como uma necessidade óbvia na cena urbana. Ao contrário dos demais recursos físicos presentes na paisagem urbana, observa-se que comumente a vegetação urbana é mais relacionada unicamente com a satisfação psicológica por ela propiciada, negligenciando-se os demais serviços ambientais que são prestados por estas estruturas naturais.

Tian et al. (2014) discutem que os espaços verdes são importantes entidades naturais e culturais da cidades, que possibilitam múltiplos benefícios a população citadina. Destacam-se os serviços ambientais, tais como a purificação do ar (SHAN et al., 2007; JIM e CHEN, 2008) e a amenização do efeito de ilha de calor (MAIMAITIYIMING et al., 2014) ; os benefícios psicológicos (FULLER et al., 2007), tais como a redução do estresse; e os benefícios associados a melhoria da saúde física, possibilitando por exemplo o prolongamento da expectativa de vida de idosos em grandes cidades (TAKANO et al., 2002). Complementando as funcionalidades ambientais apontadas, Nucci e Cavalheiro (1999) afirmam que a cobertura vegetal pode atuar como obstáculo contra o vento, na proteção da qualidade da água, no equilíbrio do índice de umidade, na redução dos ruídos, na captação de água e proteção das nascentes e mananciais, entre outras possibilidades.

No que se refere ao estritamente biótico, a cobertura vegetal em áreas urbanas também cumpre um papel estratégico na diminuição da aridez da matriz urbana, garantindo uma maior permeabilidade do fluxo gênico, bem como uma conexão entre fragmentos maiores situados nas áreas periféricas (LÖFVENHAFT et al., 2002).

Ao compreender esses benefícios promovidos pela cobertura vegetal em áreas urbanas, releva-se a importância da análise da sua dinâmica de distribuição associada ao processo de crescimento das cidades, para que então se disponha de informações que subsidiem diretrizes de gestão ambiental que contenham estratégias para a manutenção de uma boa estrutura de configuração de cobertura vegetal nas paisagens urbanizadas.

\section{Caracterização espacial da paisagem urbana de Santa Maria}

A cidade de Santa Maria (Figura 1) está situada em uma área de transição geomorfológica entre a
Depressão Central do Rio Grande do Sul e a escarpa do Planalto Meridional Brasileiro (ROSS, 
2001), possuindo uma formação vegetal transicional entre as paisagens florestais da Mata Atlântica (Floresta Estacional Decidual) e as paisagens campestres do Pampa gaúcho (CPRM, 2009; IBGE, 2012).

O recuo da escarpa da Serra Geral por erosão remontante resulta na formação, junto ao sítio urbano da cidade, de um conjunto de relevos residuais (morros testemunhos), que sustentam fragmentos florestais com diferentes níveis de conectividade, que testemunham os limites pretéritos do ecossistema florestal neste território. Nesse sentido destacam-se os setores centro-leste e norte da área urbana, onde estão situados os morros Cerrito, Mariano da Rocha e Cechela.

Figura 1. Localização da cidade de Santa Maria no estado do Rio Grande do Sul, com o perímetro urbano em destaque.

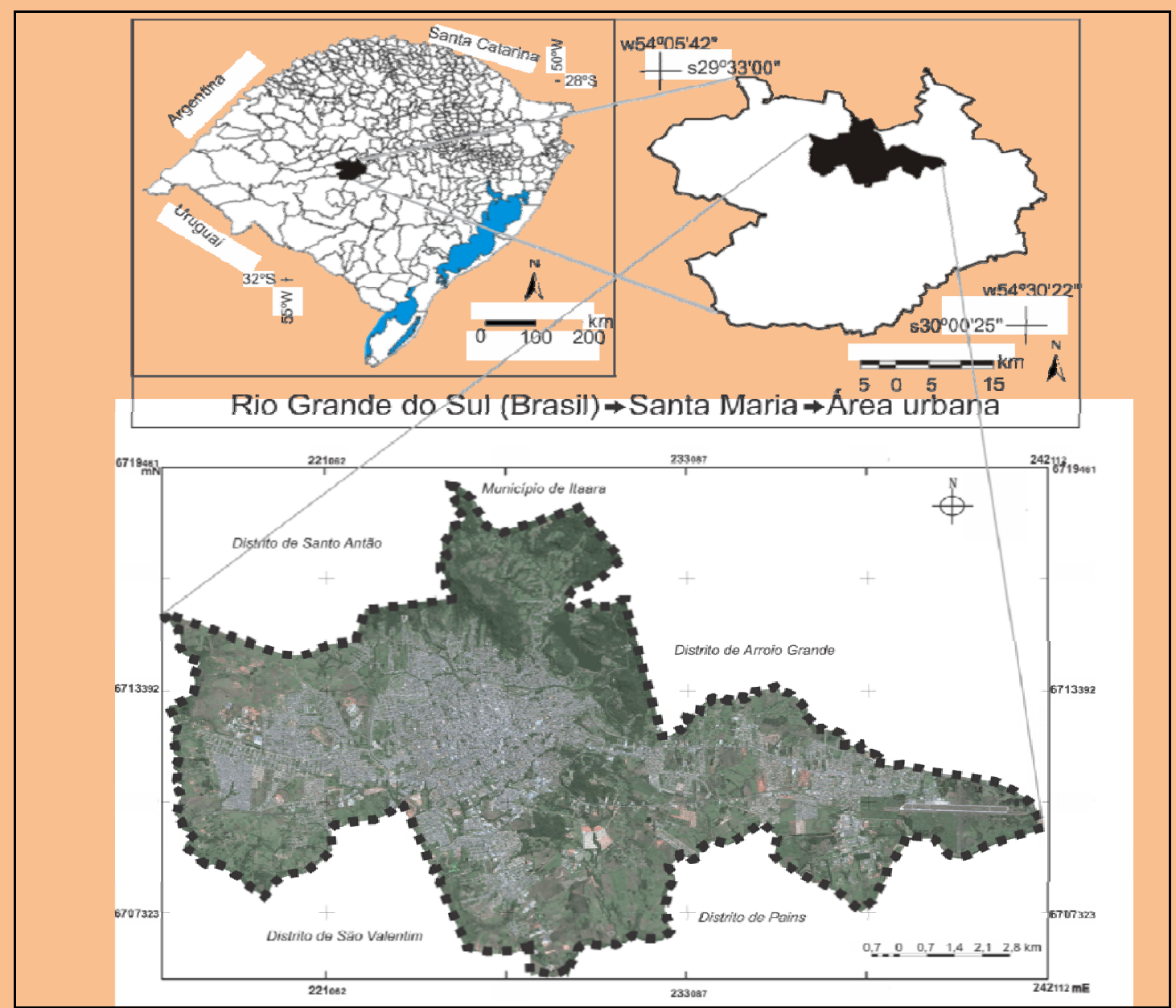

Fonte: organizado pelo autor. A imagem do perímetro urbano foi extraída do software Google Earth, e corresponde a imagem Geoeye de 21/09/2011.

Originalmente com a maior parte do atual sítio urbano recoberto por uma Floresta Estacional Decidual, a cidade de Santa Maria é um exemplo de cidade média com acelerado crescimento, em que o verde urbano foi sendo suprimido, cedendo espaço às edificações e às vias de circulação, sem preocupações com a conservação do patrimônio biótico original.

Contando atualmente com 261.027 habitantes (IBGE, 2010), a cidade teve grandes impulsos de crescimento associados, na primeira metade do século $\mathrm{XX}$, ao seu Daniel Borini Aves e Adriano Severo Figueiró 
caráter de principal entroncamento ferroviário do estado e, na segunda metade do século XX, ao papel de polo regional de serviços, especialmente ligados ao setor educacional e militar. Cada um destes impulsos de crescimento representou (e representa até hoje) perdas significativas da cobertura vegetal original, ainda mais agravada pelo quase inexistente equipamento urbano de lazer associado a parques e/ou grandes áreas verdes.

\section{MATERIAIS E MÉTODOS}

Contou-se com os seguintes materiais: levantamento aerofotogramétrico datado de janeiro de 1980, composto por 173 fotografias aéreas de alta resolução espacial, geradas na escala aproximada de 1:7.000; fragmentos da imagem Geoeye, de alta resolução espacial $(0,64 \mathrm{~m})$, datada de 21/09/2011, extraída do software Google Earth

\section{1 .}

As fotografias aéreas necessitaram de tratamento anteriormente à importação em um banco de dados no software Spring, onde foram mosaicadas para a obtenção de um produto cartográfico único. A imagem Geoeye de 2011 foi importada e registrada diretamente. O georreferenciamento do mosaico e da imagem foi feito com base em uma imagem já registrada (imagem do sensor HRC/CBERS 2B).

A partir desse ponto, definiram-se as classes a serem obtidas com base no mosaico de fotografias aéreas de 1980 e na imagem de 2011, e optou-se, de acordo com a disponibilidade dos produtos cartográficos, pela extração de 4 classes em cada mapa: Cobertura Vegetal Arbórea; Cobertura Vegetal Herbácea e Arbustiva; Espaços Construídos; e Rede de drenagem.

Na primeira classe foram incluídas as áreas com presença de cobertura vegetal de porte arbóreo. $\mathrm{Na}$ segunda, devido à impossibilidade de distinguir claramente na escala de análise (1:10.000), a diferenciação entre vegetação de porte herbáceo e arbustivo nos referenciais de 1980 e 2011, optou-se por incluí-las na mesma classe. Nesta classe ainda foram incluídas algumas áreas de uso rural situadas em algumas zonas de transição urbana-rural. A terceira classe, denominada Espaços Construídos, incorporou todas as áreas edificadas e vias de circulação, incluindo-se ainda as áreas de solos expostos. A rede de drenagem incluiu os canais de água situados na zona urbana, e os seus reservatórios de água, sendo aqui classificadas segundo a sua hierarquia fluvial.

Definidas as classes, partiu-se para a classificação dos materiais disponíveis, iniciando pelo referencial de 2011. A imagem foi classificada com um algoritmo por leitura de pixel, baseado no classificador Maxver ${ }^{4}$ (Máxima verossimilhança), a partir da aquisição de polígonos amostrais de treinamento e teste. O resultado dessa classificação foi supervisionado e otimizado, resultando no "Mapa de distribuição da cobertura vegetal da área urbana de Santa Maria (2011)”, onde foram incluídos, junto às classes temáticas, os planos de informação referentes às divisões de bairros, Regiões Administrativas ${ }^{5}$ (RAs) e a rede de drenagem.

O mesmo procedimento se deu com o referencial de 1980, classificando-se a partir da aquisição de amostras de teste e treinamento, utilizando o classificador Maxver. A imagem passou por um processo de supervisão, mais detalhado que o realizado na imagem de 2011, pois o mosaico apresentava determinadas fotografias com níveis de contrastes diferenciados, que dificultavam a classificação. A rede de drenagem, pelo

\footnotetext{
${ }^{4}$ Este método de classificação tende a superestimar a vegetação arbórea, já que muitas vezes classifica áreas de relvado e algumas áreas de solo exposto como copa de árvores (Costa et al, 2012). Para superar esse problema, foi adquirida uma maior quantidade de amostras de aquisição e teste (Ribeiro e Centeno, 2001).

${ }^{5}$ Regiões Administrativas (RAs) correspondem a um agrupamento de bairros por setor geográfico da cidade, definidos pelo Poder Público Municipal de Santa Maria.
} 
fato de não apresentar mudanças significativas entre as datas, teve a utilização do mesmo plano de informação. Para fins de comparação, optou-se pela utilização dos mesmos limites administrativos sobre os dois produtos cartográficos gerados, mesmo que os bairros em 1980 não tivessem os limites vigentes em 2011.

A análise da precisão dos mapeamentos foi realizada com base na análise da matriz de erro de classificação, utilizando os valores de desempenho geral, confusão média e estatística de kappa, que de acordo com Landis e Koch (1977), considera-se a exatidão da classificação ótima se o índice for superior a 0,81. A partir dos valores de confusão média da análise amostral, e considerando que as classificações passaram por uma supervisão visual detalhada para a sua otimização, foi definida uma margem de erro percentual com fins de comparação entre as datas. Salienta-se que o estabelecimento da margem de erro é relevante devido a que se trabalha de uma comparação entre classificações originadas a partir de produtos base distintos.
Assim, as medidas das classes de cada mapa foram tabeladas de acordo com a divisão de bairros e RAs de 2011, permitindo análises quantitativas de retração/expansão das classes mapeadas nessas unidades territoriais. Para além da análise do total de área por classe de acordo com os bairros, buscou-se aprofundar a análise da distribuição dos fragmentos arbóreos em 1980 e 2011. Para isso, foram observadas e descritas as configurações da cobertura vegetal de acordo com os valores de porcentagem arborizada e a porcentagem de cobertura vegetal total de cada bairro e região administrativa. A partir dos valores da variação de cobertura vegetal total por unidade de bairro, definiram-se classes de perda de porcentagem de vegetação (0 a 5\%; 5 a 10\%; 10 a 15\%; 15 a 20\%; 20 a $25 \%$; $>25 \%$ ) e gerou-se um mapa que identificou as zonas de perdas com maiores e menores intensidades no período analisado.

\section{RESULTADOS E DISCUSSÃO}

\section{Variação da cobertura vegetal na área urbana de Santa Maria (1980-2011)}

Com base na classificação dos mosaicos de fotografias aéreas de 1980, elaborou-se o mapa de distribuição da cobertura vegetal da área urbana de Santa Maria para aquele período (Figura 2). A partir desse mapeamento, geraram-se informações por bairros e regiões administrativas da área urbana de Santa Maria (Tabela 1). A análise amostral da classificação indicou um desempenho geral de 93,43\%, com uma confusão média de 6,57\%. O índice de kappa indica excelência na exatidão de classificação $(0,824)$.

Na RA Centro Urbano, na classe de "Espaços construídos”, em 1980 a porcentagem de cobertura foi de aproximadamente 53\%, o que já revelava um adensamento de edificações nos bairros centrais da cidade. Neste ponto destacaram-se os bairros Bonfim e Centro, com aproximadamente $70 \%$ de áreas edificadas. A observação da distribuição da cobertura vegetal indicou que mesmo com o adensamento das edificações, foi possível perceber uma série de fragmentos de vegetação arbórea, embora já configurados de forma isolada.

A RA Norte apresentou em 1980 a formação de alguns bairros com avanço das áreas edificadas, apesar de contar com apenas $17,81 \%$ de sua área incluída na classe de espaços construídos. A predominância da Daniel Borini Aves e Adriano Severo Figueiró 
cobertura vegetal nesta região associou-se ao fato de que parte desses bairros apresentava extensas áreas arborizadas associadas às áreas de APP na encosta da Serra Geral, como no caso dos bairros Chácara das Flores e Nossa Senhora do Perpétuo Socorro, com porcentagens de 60,29\% e 66,74\% de cobertura vegetal arbórea.
Na RA Nordeste, alguns bairros também possuíam áreas junto à encosta da Serra Geral, tais como o bairro Campestre Menino Deus, o Km 3 e o bairro Itararé (em contato com o morro Cechela), que elevaram sua porcentagem de cobertura vegetal arbórea (aproximadamente 49\%).

Figura 2. Mapa de distribuição da cobertura vegetal na área urbana de Santa Maria (1980).

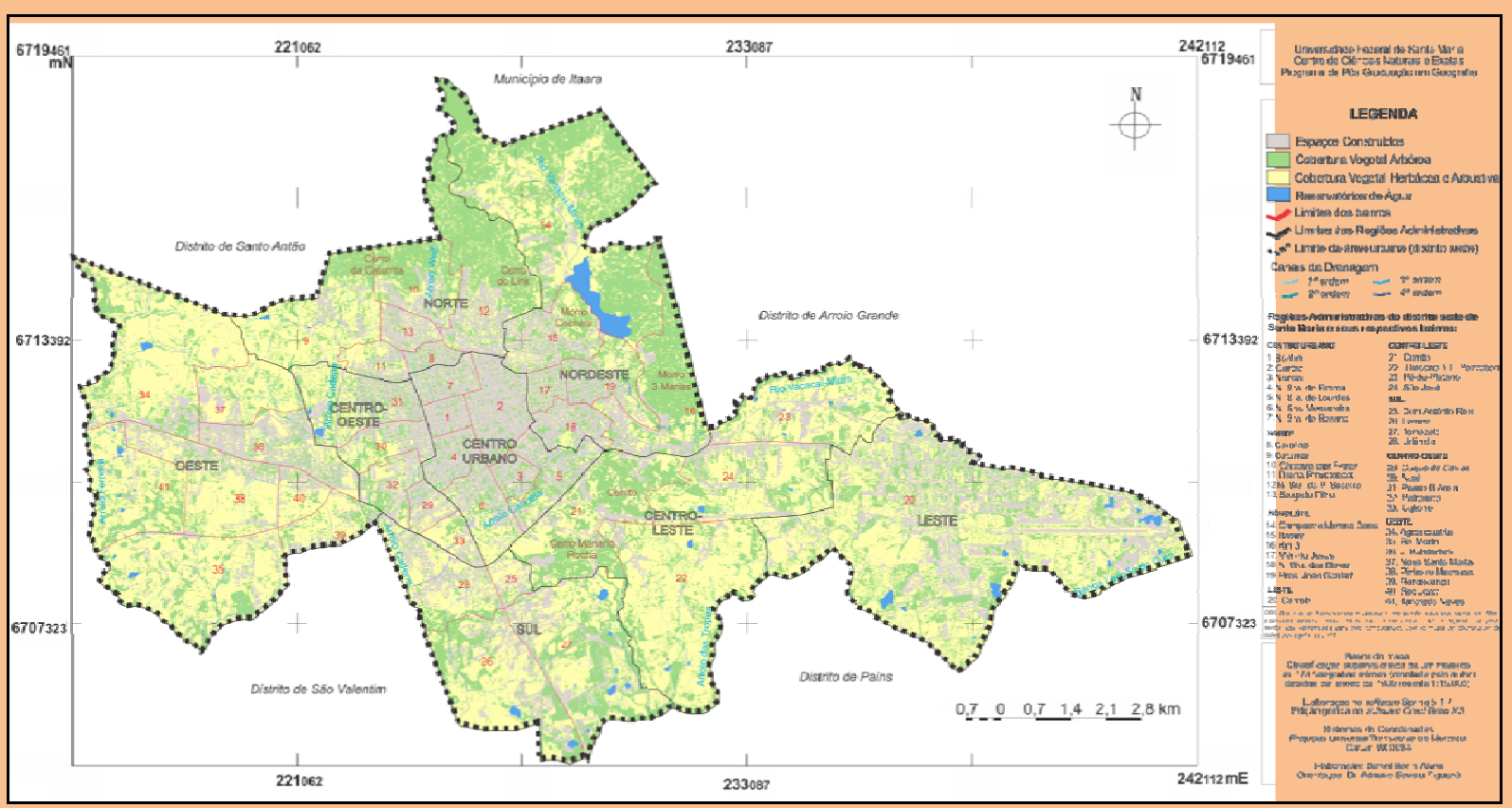

Fonte: elaborado pelos autores. 
Tabela 1. Uso e cobertura da terra por unidades de bairros da área urbana de Santa Maria (1980).

\begin{tabular}{|c|c|c|c|c|c|c|c|c|c|c|}
\hline \multirow{3}{*}{ RAs } & \multirow{3}{*}{ Bairro } & \multirow{3}{*}{$\begin{array}{c}\text { Área } \\
\text { total } \\
\text { (ha) }\end{array}$} & \multicolumn{8}{|c|}{ "Uso e cobertura da terra* } \\
\hline & & & \multicolumn{2}{|c|}{ EC } & \multicolumn{2}{|c|}{ CVA } & \multicolumn{2}{|c|}{ CVHA } & \multicolumn{2}{|c|}{ RD } \\
\hline & & & (ha) & $(\%)$ & (ha) & $(\%)$ & (ha) & $(\%)$ & (ha) & $(\%)$ \\
\hline \multirow{8}{*}{ 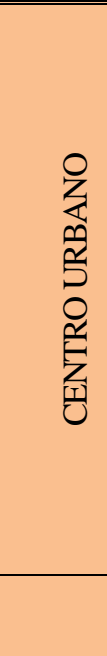 } & Bonfim & 55,46 & 37,91 & $\begin{array}{c}68,3 \\
6\end{array}$ & 13,83 & $\begin{array}{c}24,9 \\
4\end{array}$ & 3,72 & 6,71 & 0,00 & $\begin{array}{c}0,0 \\
0\end{array}$ \\
\hline & Centro & 190,44 & $\begin{array}{c}131,4 \\
4\end{array}$ & $\begin{array}{c}69,0 \\
2\end{array}$ & 46,70 & $\begin{array}{c}24,5 \\
2\end{array}$ & 12,11 & 6,36 & 0,19 & $\begin{array}{c}0,1 \\
0\end{array}$ \\
\hline & Nonoai & 60,91 & 30,64 & $\begin{array}{c}50,3 \\
0\end{array}$ & 22,81 & $\begin{array}{c}37,4 \\
5\end{array}$ & 7,22 & $\begin{array}{c}11,8 \\
5\end{array}$ & 0,24 & $\begin{array}{c}0,3 \\
9\end{array}$ \\
\hline & Nossa Sra. de Fátima & 91,48 & 53,68 & $\begin{array}{c}58,6 \\
8 \\
\end{array}$ & 30,12 & $\begin{array}{c}32,9 \\
3 \\
\end{array}$ & 7,36 & 8,05 & 0,32 & $\begin{array}{c}0,3 \\
5 \\
\end{array}$ \\
\hline & Nossa Sra. de Lourdes & 162,34 & 65,21 & $\begin{array}{c}40,1 \\
7\end{array}$ & 66,32 & $\begin{array}{c}40,8 \\
5\end{array}$ & 30,41 & $\begin{array}{c}18,7 \\
3 \\
\end{array}$ & 0,41 & $\begin{array}{c}0,2 \\
5 \\
\end{array}$ \\
\hline & Nossa Sra. Medianeira & 162,12 & 50,56 & $\begin{array}{c}31,1 \\
9\end{array}$ & 54,40 & $\begin{array}{c}33,5 \\
6\end{array}$ & 56,58 & $\begin{array}{c}34,9 \\
0\end{array}$ & 0,58 & $\begin{array}{c}0,3 \\
6\end{array}$ \\
\hline & Nossa Sra. do Rosário & 84,77 & 55,77 & $\begin{array}{c}65,7 \\
9 \\
\end{array}$ & 21,33 & $\begin{array}{c}25,1 \\
6\end{array}$ & 7,49 & 8,84 & 0,18 & $\begin{array}{c}0,2 \\
1 \\
\end{array}$ \\
\hline & TOTAL & 807,52 & $\begin{array}{c}425,2 \\
1 \\
\end{array}$ & $\begin{array}{c}52,6 \\
6 \\
\end{array}$ & $\begin{array}{c}255,5 \\
1\end{array}$ & $\begin{array}{c}31,6 \\
4 \\
\end{array}$ & $\begin{array}{c}124,8 \\
9\end{array}$ & $\begin{array}{c}15,4 \\
7\end{array}$ & 1,92 & $\begin{array}{c}0,2 \\
4\end{array}$ \\
\hline \multirow{7}{*}{ 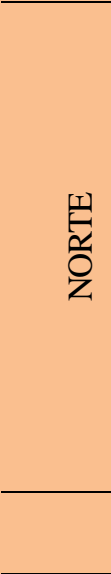 } & Carolina & 46,63 & 25,35 & $\begin{array}{c}54,3 \\
6\end{array}$ & 15,79 & $\begin{array}{c}33,8 \\
6\end{array}$ & 5,26 & $\begin{array}{c}11,2 \\
8\end{array}$ & 0,23 & $\begin{array}{c}0,4 \\
9\end{array}$ \\
\hline & Caturrita & 393,09 & 23,52 & 5,98 & $\begin{array}{c}133,5 \\
7\end{array}$ & $\begin{array}{c}33,9 \\
8\end{array}$ & $\begin{array}{c}232,1 \\
7\end{array}$ & $\begin{array}{c}59,0 \\
6\end{array}$ & 3,82 & $\begin{array}{c}0,9 \\
7\end{array}$ \\
\hline & Chácara das Flores & 225,8 & 36,93 & $\begin{array}{c}16,3 \\
6\end{array}$ & $\begin{array}{c}136,1 \\
3\end{array}$ & $\begin{array}{c}60,2 \\
9\end{array}$ & 51,77 & $\begin{array}{c}22,9 \\
3\end{array}$ & 0,97 & $\begin{array}{c}0,4 \\
3\end{array}$ \\
\hline & Divina Providência & 81,95 & 21,41 & $\begin{array}{c}26,1 \\
3\end{array}$ & 22,33 & $\begin{array}{c}27,2 \\
5\end{array}$ & 37,85 & $\begin{array}{c}46,1 \\
9\end{array}$ & 0,36 & $\begin{array}{c}0,4 \\
4\end{array}$ \\
\hline & $\begin{array}{l}\text { Nossa Sra. do Perpétuo } \\
\text { Socorro }\end{array}$ & 458,61 & 74,03 & $\begin{array}{c}16,1 \\
4\end{array}$ & $\begin{array}{c}306,0 \\
8\end{array}$ & $\begin{array}{c}66,7 \\
4\end{array}$ & 77,79 & $\begin{array}{c}16,9 \\
6\end{array}$ & 0,71 & $\begin{array}{c}0,1 \\
5\end{array}$ \\
\hline & Salgado Filho & 76,56 & 40,73 & $\begin{array}{c}53,2 \\
0\end{array}$ & 17,05 & $\begin{array}{c}22,2 \\
7\end{array}$ & 18,61 & $\begin{array}{c}24,3 \\
1\end{array}$ & 0,17 & $\begin{array}{c}0,2 \\
2\end{array}$ \\
\hline & TOTAL & 1282,64 & $\begin{array}{c}221,9 \\
7\end{array}$ & $\begin{array}{c}17,3 \\
1 \\
\end{array}$ & $\begin{array}{c}630,9 \\
4 \\
\end{array}$ & $\begin{array}{c}49,1 \\
9 \\
\end{array}$ & $\begin{array}{c}423,4 \\
5 \\
\end{array}$ & $\begin{array}{c}33,0 \\
1 \\
\end{array}$ & 6,26 & $\begin{array}{c}0,4 \\
9 \\
\end{array}$ \\
\hline \multirow{7}{*}{ 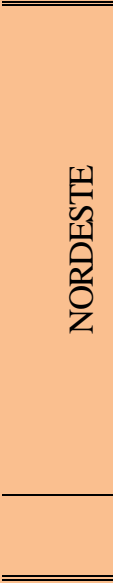 } & Campestre Menino Deus & 1089,78 & 32,17 & 2,95 & $\begin{array}{c}687,9 \\
6 \\
\end{array}$ & $\begin{array}{c}63,1 \\
3 \\
\end{array}$ & $\begin{array}{c}310,3 \\
1 \\
\end{array}$ & $\begin{array}{c}28,4 \\
7 \\
\end{array}$ & 59,34 & $\begin{array}{c}5,4 \\
5 \\
\end{array}$ \\
\hline & Itararé & 222,41 & 69,03 & $\begin{array}{c}31,0 \\
4\end{array}$ & $\begin{array}{c}102,0 \\
2\end{array}$ & $\begin{array}{c}45,8 \\
7\end{array}$ & 51,27 & $\begin{array}{c}23,0 \\
5\end{array}$ & 0,09 & $\begin{array}{c}0,0 \\
4\end{array}$ \\
\hline & $\mathrm{Km} 3$ & 377,73 & 59,33 & $\begin{array}{c}15,7 \\
1\end{array}$ & $\begin{array}{c}261,8 \\
5\end{array}$ & $\begin{array}{c}69,3 \\
2 \\
\end{array}$ & 55,99 & $\begin{array}{c}14,8 \\
2\end{array}$ & 0,56 & $\begin{array}{c}0,1 \\
5\end{array}$ \\
\hline & Menino Jesus & 58,13 & 32,54 & $\begin{array}{c}55,9 \\
8\end{array}$ & 18,83 & $\begin{array}{c}32,3 \\
9\end{array}$ & 6,76 & $\begin{array}{c}11,6 \\
3 \\
\end{array}$ & 0,00 & $\begin{array}{c}0,0 \\
0 \\
\end{array}$ \\
\hline & Nossa Sra. das Dores & 112,37 & 62,14 & $\begin{array}{c}55,3 \\
0\end{array}$ & 32,39 & $\begin{array}{c}28,8 \\
2\end{array}$ & 17,66 & $\begin{array}{c}15,7 \\
2\end{array}$ & 0,18 & $\begin{array}{c}0,1 \\
6\end{array}$ \\
\hline & Pres. Joao Goulart & 178,06 & 58,32 & $\begin{array}{c}32,7 \\
5\end{array}$ & 74,40 & $\begin{array}{c}41,7 \\
8\end{array}$ & 44,35 & $\begin{array}{c}24,9 \\
1\end{array}$ & 0,99 & $\begin{array}{c}0,5 \\
6\end{array}$ \\
\hline & TOTAL & 2038,48 & $\begin{array}{c}313,5 \\
3 \\
\end{array}$ & $\begin{array}{c}15,3 \\
8 \\
\end{array}$ & $\begin{array}{c}1177,4 \\
5 \\
\end{array}$ & $\begin{array}{c}57,7 \\
6 \\
\end{array}$ & $\begin{array}{c}486,3 \\
4 \\
\end{array}$ & $\begin{array}{c}23,8 \\
6 \\
\end{array}$ & 61,16 & $\begin{array}{c}3,0 \\
0 \\
\end{array}$ \\
\hline \multirow[t]{2}{*}{ 点 } & Camobi & 2040,29 & $\begin{array}{c}392,5 \\
0\end{array}$ & $\begin{array}{c}19,2 \\
4\end{array}$ & $\begin{array}{c}632,9 \\
7\end{array}$ & $\begin{array}{c}31,0 \\
2\end{array}$ & $\begin{array}{c}988,1 \\
1\end{array}$ & $\begin{array}{c}48,4 \\
3\end{array}$ & 26,71 & $\begin{array}{c}1,3 \\
1\end{array}$ \\
\hline & TOTAL & 2040,29 & $\begin{array}{c}392,5 \\
0\end{array}$ & $\begin{array}{c}19,2 \\
4\end{array}$ & $\begin{array}{c}632,9 \\
7\end{array}$ & $\begin{array}{c}31,0 \\
2\end{array}$ & $\begin{array}{c}988,1 \\
1\end{array}$ & $\begin{array}{c}48,4 \\
3\end{array}$ & 26,71 & $\begin{array}{c}1,3 \\
1 \\
\end{array}$ \\
\hline 101 & Cerrito & 462,13 & 63,34 & 13,7 & 261,5 & 56,5 & 136,8 & 29,6 & 0,41 & 0,0 \\
\hline
\end{tabular}

Daniel Borini Aves e Adriano Severo Figueiró 


\begin{tabular}{|c|c|c|c|c|c|c|c|c|c|c|}
\hline & & & & 1 & 4 & 9 & 4 & 1 & & 9 \\
\hline & $\begin{array}{c}\text { Diácono João Luiz } \\
\text { Pozzobon }\end{array}$ & 775,23 & 21,72 & 2,80 & $\begin{array}{c}225,8 \\
9 \\
\end{array}$ & $\begin{array}{c}29,1 \\
4 \\
\end{array}$ & $\begin{array}{c}522,7 \\
4\end{array}$ & $\begin{array}{c}67,4 \\
3 \\
\end{array}$ & 4,88 & $\begin{array}{c}0,6 \\
3 \\
\end{array}$ \\
\hline & Pé-de-Plátano & 411,60 & 45,24 & $\begin{array}{c}10,9 \\
9 \\
\end{array}$ & $\begin{array}{c}115,3 \\
5 \\
\end{array}$ & $\begin{array}{c}28,0 \\
2 \\
\end{array}$ & $\begin{array}{c}247,6 \\
1 \\
\end{array}$ & $\begin{array}{c}60,1 \\
6 \\
\end{array}$ & 3,4 & $\begin{array}{c}0,8 \\
3 \\
\end{array}$ \\
\hline & São José & 466 & 69,28 & $\begin{array}{c}14,8 \\
7 \\
\end{array}$ & $\begin{array}{c}158,6 \\
0\end{array}$ & $\begin{array}{c}34,0 \\
3 \\
\end{array}$ & $\begin{array}{c}234,8 \\
8 \\
\end{array}$ & $\begin{array}{c}50,4 \\
0 \\
\end{array}$ & 3,24 & $\begin{array}{c}0,7 \\
0 \\
\end{array}$ \\
\hline & TOTAL & 2114,96 & $\begin{array}{c}199,5 \\
8 \\
\end{array}$ & 9,44 & $\begin{array}{c}761,3 \\
8 \\
\end{array}$ & $\begin{array}{c}36,0 \\
0 \\
\end{array}$ & $\begin{array}{c}1142,0 \\
7 \\
\end{array}$ & $\begin{array}{c}54,0 \\
0 \\
\end{array}$ & 11,93 & $\begin{array}{c}0,5 \\
6 \\
\end{array}$ \\
\hline \multirow{5}{*}{ s } & Dom Antônio Reis & 62,42 & 12,82 & $\begin{array}{c}20,5 \\
4\end{array}$ & 15,31 & $\begin{array}{c}24,5 \\
3\end{array}$ & 34,12 & $\begin{array}{c}54,6 \\
6\end{array}$ & 0,17 & $\begin{array}{c}0,2 \\
7\end{array}$ \\
\hline & Lorenzi & 484,73 & 63,41 & $\begin{array}{c}13,0 \\
8\end{array}$ & $\begin{array}{c}163,4 \\
2\end{array}$ & $\begin{array}{c}33,7 \\
1\end{array}$ & $\begin{array}{c}250,6 \\
5\end{array}$ & $\begin{array}{c}51,7 \\
1\end{array}$ & 7,25 & $\begin{array}{c}1,5 \\
0\end{array}$ \\
\hline & Tomazetti & 585,44 & 85,72 & $\begin{array}{c}14,6 \\
4\end{array}$ & $\begin{array}{c}239,8 \\
1\end{array}$ & $\begin{array}{c}40,9 \\
6\end{array}$ & $\begin{array}{c}250,7 \\
0\end{array}$ & $\begin{array}{c}42,8 \\
2\end{array}$ & 9,21 & $\begin{array}{c}1,5 \\
7\end{array}$ \\
\hline & Urlândia & 273,88 & 58,75 & $\begin{array}{c}21,4 \\
5\end{array}$ & 78,26 & $\begin{array}{c}28,5 \\
7\end{array}$ & $\begin{array}{c}135,5 \\
6\end{array}$ & $\begin{array}{c}49,5 \\
0\end{array}$ & 1,31 & $\begin{array}{c}0,4 \\
8\end{array}$ \\
\hline & TOTAL & 1406,47 & $\begin{array}{c}220,7 \\
0\end{array}$ & $\begin{array}{c}15,6 \\
9\end{array}$ & $\begin{array}{c}496,8 \\
0\end{array}$ & $\begin{array}{c}35,3 \\
2\end{array}$ & $\begin{array}{c}671,0 \\
3\end{array}$ & $\begin{array}{c}47,7 \\
1\end{array}$ & 17,94 & $\begin{array}{c}1,2 \\
8\end{array}$ \\
\hline \multirow{6}{*}{ 空 } & Duque de Caxias & 65,8 & 29,03 & $\begin{array}{c}44,1 \\
2\end{array}$ & 15,51 & $\begin{array}{c}23,5 \\
7\end{array}$ & 20,96 & $\begin{array}{c}31,8 \\
5\end{array}$ & 0,3 & $\begin{array}{c}0,4 \\
6\end{array}$ \\
\hline & Noal & 124 & 39,17 & $\begin{array}{c}31,5 \\
9\end{array}$ & 45,08 & $\begin{array}{c}36,3 \\
5\end{array}$ & 39,34 & $\begin{array}{c}31,7 \\
3\end{array}$ & 0,41 & $\begin{array}{c}0,3 \\
3\end{array}$ \\
\hline & Passo D’Areia & 265,37 & 69,28 & $\begin{array}{c}26,1 \\
1\end{array}$ & 95,93 & $\begin{array}{c}36,1 \\
5\end{array}$ & 96,75 & $\begin{array}{c}36,4 \\
6\end{array}$ & 3,41 & $\begin{array}{c}1,2 \\
8\end{array}$ \\
\hline & Patronato & 118,32 & 37,34 & $\begin{array}{c}31,5 \\
6\end{array}$ & 44,68 & $\begin{array}{c}37,7 \\
6\end{array}$ & 36,06 & $\begin{array}{c}30,4 \\
8\end{array}$ & 0,24 & $\begin{array}{c}0,2 \\
0\end{array}$ \\
\hline & Uglione & 67,79 & 16,89 & $\begin{array}{c}24,9 \\
2\end{array}$ & 19,41 & $\begin{array}{c}28,6 \\
3\end{array}$ & 31,32 & $\begin{array}{c}46,2 \\
0\end{array}$ & 0,17 & $\begin{array}{c}0,2 \\
5\end{array}$ \\
\hline & TOTAL & 641,28 & $\begin{array}{c}191,7 \\
1 \\
\end{array}$ & $\begin{array}{c}29,8 \\
9 \\
\end{array}$ & $\begin{array}{c}220,6 \\
1 \\
\end{array}$ & $\begin{array}{c}34,4 \\
0 \\
\end{array}$ & $\begin{array}{c}224,4 \\
3 \\
\end{array}$ & $\begin{array}{c}35,0 \\
0\end{array}$ & 4,53 & $\begin{array}{c}0,7 \\
1 \\
\end{array}$ \\
\hline \multirow{9}{*}{ 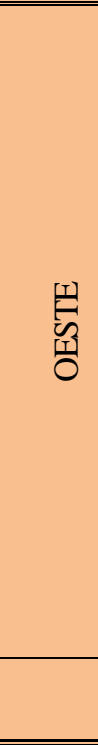 } & Agroindustrial & 651,18 & 45,38 & 6,97 & $\begin{array}{c}141,3 \\
6\end{array}$ & $\begin{array}{c}21,7 \\
1\end{array}$ & $\begin{array}{c}457,4 \\
7\end{array}$ & $\begin{array}{c}70,2 \\
5\end{array}$ & 6,97 & $\begin{array}{c}1,0 \\
7\end{array}$ \\
\hline & Boi Morto & 583,82 & 44,60 & 7,64 & $\begin{array}{c}173,1 \\
7\end{array}$ & $\begin{array}{c}29,6 \\
6\end{array}$ & $\begin{array}{c}361,7 \\
6\end{array}$ & $\begin{array}{c}61,9 \\
6\end{array}$ & 4,29 & $\begin{array}{c}0,7 \\
3\end{array}$ \\
\hline & Juscelino Kubitschek & 247,98 & $\begin{array}{c}113,0 \\
8\end{array}$ & $\begin{array}{c}45,6 \\
0 \\
\end{array}$ & 61,42 & $\begin{array}{c}24,7 \\
7\end{array}$ & 72,70 & $\begin{array}{c}29,3 \\
2 \\
\end{array}$ & 0,78 & $\begin{array}{c}0,3 \\
1\end{array}$ \\
\hline & Nova Santa Marta & 207,4 & 27,46 & $\begin{array}{c}13,2 \\
4\end{array}$ & 46,20 & $\begin{array}{c}22,2 \\
8\end{array}$ & $\begin{array}{c}132,9 \\
6\end{array}$ & $\begin{array}{c}64,1 \\
1\end{array}$ & 0,78 & $\begin{array}{c}0,3 \\
8\end{array}$ \\
\hline & Pinheiro Machado & 356,34 & 61,70 & $\begin{array}{c}17,3 \\
1\end{array}$ & 77,13 & $\begin{array}{c}21,6 \\
5\end{array}$ & $\begin{array}{c}217,1 \\
6\end{array}$ & $\begin{array}{c}60,9 \\
4\end{array}$ & 0,35 & $\begin{array}{c}0,1 \\
0\end{array}$ \\
\hline & Renascença & 141,86 & 17,65 & $\begin{array}{c}12,4 \\
4\end{array}$ & 43,80 & $\begin{array}{c}30,8 \\
8\end{array}$ & 79,74 & $\begin{array}{c}56,2 \\
1\end{array}$ & 0,67 & $\begin{array}{c}0,4 \\
7\end{array}$ \\
\hline & São João & 85,17 & 15,10 & $\begin{array}{c}17,7 \\
3 \\
\end{array}$ & 17,75 & $\begin{array}{c}20,8 \\
4 \\
\end{array}$ & 52,09 & $\begin{array}{c}61,1 \\
6 \\
\end{array}$ & 0,23 & $\begin{array}{c}0,2 \\
7\end{array}$ \\
\hline & Tancredo Neves & 340,41 & 19,60 & 5,76 & $\begin{array}{c}118,6 \\
0\end{array}$ & $\begin{array}{c}34,8 \\
4\end{array}$ & $\begin{array}{c}198,2 \\
0\end{array}$ & $\begin{array}{c}58,2 \\
2\end{array}$ & 4,01 & $\begin{array}{c}1,1 \\
8\end{array}$ \\
\hline & TOTAL & 2614,16 & $\begin{array}{c}344,5 \\
7 \\
\end{array}$ & $\begin{array}{c}13,1 \\
8 \\
\end{array}$ & $\begin{array}{c}679,4 \\
3 \\
\end{array}$ & $\begin{array}{c}25,9 \\
9 \\
\end{array}$ & $\begin{array}{c}1572,0 \\
8 \\
\end{array}$ & $\begin{array}{c}60,1 \\
4 \\
\end{array}$ & 18,08 & $\begin{array}{c}0,6 \\
9 \\
\end{array}$ \\
\hline $\begin{array}{c}\text { TOD } \\
\text { AS }\end{array}$ & TOTAL & 12945,8 & $\begin{array}{c}2309,7 \\
7\end{array}$ & $\begin{array}{c}17,8 \\
4\end{array}$ & $\begin{array}{c}4855,1 \\
0\end{array}$ & $\begin{array}{c}37,5 \\
0\end{array}$ & $\begin{array}{c}5632 \\
4\end{array}$ & $\begin{array}{c}43,5 \\
1\end{array}$ & $\begin{array}{c}148,5 \\
3\end{array}$ & $\begin{array}{c}1,1 \\
5\end{array}$ \\
\hline
\end{tabular}

RAs=Regiões Administrativas; EC= Espaços Construídos; CVA= Cobertura Vegetal Arbórea; CVHA= Cobertura Vegetal Herbácea ou Arbustiva; $\mathbf{R D}=$ Rede de Drenagem.

*Para cada classe indica-se a área ocupada (ha) e a proporção de área ocupada (\%) em relação à área total dos bairros. 
Na RA Centro-Leste, observou-se que a proporção de espaços construídos em 1980 ainda era baixa, com os fragmentos de vegetação arbórea dos morros testemunhos Cerrito e Mariano Rocha como os mais expressivos. As demais áreas ainda apresentaram alto grau de cobertura vegetal herbácea e arbustiva, em que alguns espaços estavam associados a atividades agrícolas que se processavam no interior do perímetro urbano atual da cidade.

As RAs Leste e Oeste apresentaram panoramas semelhantes em relação às classes temáticas predominantes. Ambas retrataram determinada ocupação das áreas edificadas, ainda não muito adensada, que se configuravam junto a áreas de cobertura vegetal em sua grande maioria de porte herbáceo e arbustivo, com a presença de fragmentos arbóreos mais expressivos relacionados às matas galerias junto aos canais de drenagem. Em direção a RA Oeste, destacava-se o adensamento de edificações do bairro Juscelino Kubitschek em relação aos demais bairros, que esteve associado à criação do conjunto habitacional Santa Marta.

Na RA Centro-Oeste se observou um maior avanço das áreas edificadas em relação às porcentagens das RAs Leste, Oeste e Centro-Leste, onde as áreas de cobertura vegetal arbórea estavam associadas às margens do Arroio Cadena e seus tributários. Os espaços construídos já representavam cerca de $30 \%$ da região, enquanto a cobertura vegetal ocupava cerca de 69\% da área.

Na RA Sul identificou-se baixa proporção de áreas edificadas em relação aos espaços de cobertura vegetal, que ocupavam valor inferior a $10 \%$ com relação à sua área total. Observaram-se fragmentos de vegetação arbórea bem configurados, grandes e conexos próximos aos canais de drenagem e seus arredores. $\mathrm{O}$ recobrimento de cobertura vegetal foi de cerca de 83\% da área.

Já para o ano de 2011, o avanço das áreas edificadas e o processo de diminuição da cobertura vegetal da área urbana de Santa Maria podem ser observados junto à classificação da imagem Geoeye. Com base no mapa de cobertura vegetal de 2011 (Figura 3), também se gerou as medidas de classes por unidades de bairro e regiões administrativas (Tabela 2). A matriz de erro de classificação indica desempenho geral de 98,32\%, com uma confusão média de 1,68\%, sendo o índice de kappa de 0,884 (ótimo).

O mapa de distribuição da cobertura vegetal de 2011 está claramente inserido em uma matriz de espaços construídos mais densa, onde se observa que o avanço das áreas edificadas esteve vetorizada principalmente em direção a oeste, leste e sul, enquanto a norte, apesar do aumento da área construída em relação á 1980, percebe-se uma leve tendência de estagnação do avanço urbano, em função da barreira geomorfológica da escarpa do planalto. Os fragmentos maiores e com maior grau de conectividade continuam associados às áreas de escarpa e morros testemunhos, sendo que os fragmentos de mata galeria notoriamente perderam espaço nas áreas por onde o avanço dos espaços construídos se intensifica, como o exemplo dos arredores do Arroio Cadena, a Centro-Oeste, e os arredores do Arroio Cancela, ao sul do Centro Urbano. 
Figura 3. Mapa de distribuição da cobertura vegetal na área urbana de Santa Maria (2011).

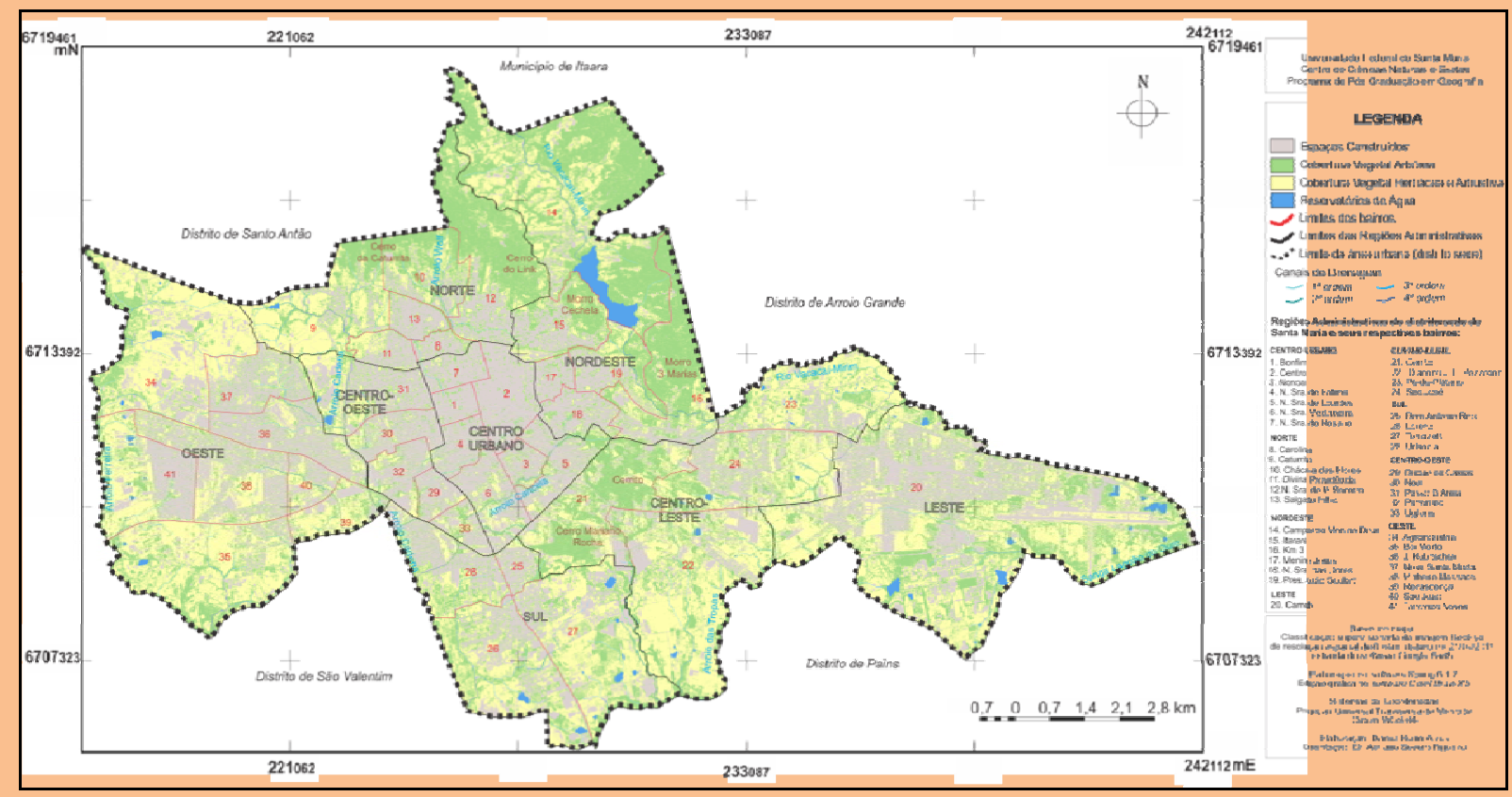

Fonte: elaborado pelos autores.

Na RA Centro Urbano todos os bairros já apresentavam em 2011 a classe de espaços construídos predominando sobre os demais, com cobertura superior a $60 \%$ de sua área total, onde os bairros Bonfim e Centro apresentam as maiores porcentagens, respectivamente $86,57 \%$ e 86,25\%. A distribuição da cobertura vegetal da região tem os bairros Nossa Senhora de Lourdes e Nossa Senhora Medianeira como destaque, onde ainda há alguns fragmentos mais agregados, enquanto nos bairros de maior adensamento urbano os fragmentos arbóreos perderam muito espaço, representados por poucos indivíduos isolados.

Nas RAs Norte e Nordeste, prossegue uma alta porcentagem de cobertura vegetal ligada aos fragmentos de vegetação associados à presença dos morros do rebordo (morros testemunhos). Nessas regiões, poucos foram os bairros em que o adensamento se intensificou bruscamente com relação a 1980, sendo esses os bairros Divina Providência (que praticamente dobrou sua porcentagem de espaços construídos, de 26,13\% para 50,71\%), Salgado Filho (de 40,73\% para
69,93\%) e Menino Jesus (de 32,54\% para 75,80\%), que justamente referem-se aos bairros mais próximos da área central da cidade. De forma geral essas duas regiões foram as que registraram o menor crescimento do adensamento das áreas edificadas $(5,67 \%$ no conjunto de bairros da RA Norte e 2,96\% nos bairros da RA Nordeste).

As RAs Centro-Oeste, Oeste e Sul também registraram altas porcentagens de avanço das áreas edificadas a custo de perda das áreas anteriormente vegetadas. 
Tabela 2. Uso e cobertura da terra por unidades de bairros da área urbana de Santa Maria (2011).

\begin{tabular}{|c|c|c|c|c|c|c|c|c|c|c|}
\hline \multirow{3}{*}{ RAs } & \multirow{3}{*}{ Bairro } & \multirow{3}{*}{$\begin{array}{l}\text { Área } \\
\text { total } \\
\text { (ha) }\end{array}$} & \multicolumn{8}{|c|}{ Uso e cobertura da terra* } \\
\hline & & & \multicolumn{2}{|c|}{ EC } & \multicolumn{2}{|c|}{ CVA } & \multicolumn{2}{|c|}{ CVHA } & \multicolumn{2}{|c|}{ RD } \\
\hline & & & (ha) & $(\%)$ & (ha) & $(\%)$ & (ha) & $(\%)$ & (ha) & $(\%)$ \\
\hline \multirow{8}{*}{ 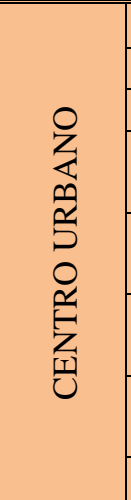 } & Bonfim & $\overline{55,46}$ & 48,01 & 86,57 & 5,55 & 10,01 & 1,90 & 3,43 & 0,00 & 0,00 \\
\hline & Centro & 190,44 & 164,26 & 86,25 & 19,09 & 10,02 & 6,9 & 3,62 & 0,19 & 0,10 \\
\hline & Nonoai & 60,91 & 41,08 & 67,44 & 13,21 & 21,69 & 6,38 & 10,47 & 0,24 & 0,39 \\
\hline & $\begin{array}{l}\text { Nossa Sra. de } \\
\text { Fátima }\end{array}$ & 91,48 & 71,05 & 77,67 & 14,01 & 15,31 & 6,1 & 6,67 & 0,32 & 0,35 \\
\hline & $\begin{array}{c}\text { Nossa Sra. de } \\
\text { Lourdes }\end{array}$ & 162,34 & 100,05 & 61,63 & 40,39 & 24,88 & 21,49 & 13,24 & 0,41 & 0,25 \\
\hline & $\begin{array}{l}\text { Nossa Sra. } \\
\text { Medianeira }\end{array}$ & 162,12 & 99,43 & 61,33 & 30,82 & 19,01 & 31,29 & 19,30 & 0,58 & 0,36 \\
\hline & $\begin{array}{c}\text { Nossa Sra. do } \\
\text { Rosário } \\
\end{array}$ & 84,77 & 65,65 & 77,44 & 12,91 & 15,23 & 6,03 & 7,11 & 0,18 & 0,21 \\
\hline & TOTAL & $\mathbf{8 0 7 , 5 2}$ & 589,53 & 73,01 & 135,98 & 16,84 & 80,09 & 9,92 & 1,92 & 0,24 \\
\hline \multirow{7}{*}{ 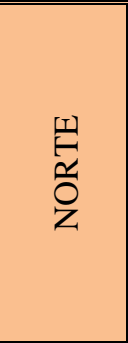 } & Carolina & 446,63 & 29,91 & $\overline{~ 64,14}$ & 11,51 & 24,68 & $4,4,98$ & 10,68 & 0,23 & 0,49 \\
\hline & Caturrita & 393,09 & 46,54 & 11,84 & 130,25 & 33,13 & 212,48 & 54,05 & 3,82 & 0,97 \\
\hline & Chácara das Flores & 225,8 & 44,77 & 19,83 & 119,44 & 52,90 & 60,62 & 26,85 & 0,97 & 0,43 \\
\hline & Divina Providência & 81,95 & 41,56 & 50,71 & 16,23 & 19,80 & 23,8 & 29,04 & 0,36 & 0,44 \\
\hline & $\begin{array}{c}\text { Nossa Sra. do } \\
\text { Perpétuo Socorro }\end{array}$ & 458,61 & 78,42 & 17,10 & 304,82 & 66,47 & 74,66 & 16,28 & 0,71 & 0,15 \\
\hline & Salgado Filho & 76,56 & 53,54 & 69,93 & 14,95 & 19,53 & 7,90 & 10,32 & 0,17 & 0,22 \\
\hline & TOTAL & 1282,64 & 294,74 & 22,98 & 597,2 & 46,56 & 384,44 & 29,97 & 6,26 & 0,49 \\
\hline \multirow{7}{*}{ 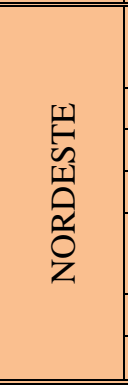 } & $\begin{array}{c}\text { Campestre Menino } \\
\text { Deus }\end{array}$ & 1089,78 & 53,87 & 4,94 & 650,34 & 59,68 & 326,23 & 29,94 & 59,34 & 5,45 \\
\hline & Itararé & 222,41 & 78,2 & 35,16 & 101,16 & 45,48 & 42,96 & 19,32 & 0,09 & 0,04 \\
\hline & $\mathrm{Km} 3$ & 377,73 & 61,16 & 16,19 & 246,62 & 65,29 & 69,39 & 18,37 & 0,56 & 0,15 \\
\hline & Menino Jesus & 58,13 & 44,03 & 75,74 & 10,46 & 17,99 & 3,64 & 6,26 & 0,00 & 0,00 \\
\hline & $\begin{array}{l}\text { Nossa Sra. das } \\
\text { Dores }\end{array}$ & 112,37 & 75,8 & 67,46 & 24,53 & 21,83 & 11,86 & 10,55 & 0,18 & 0,16 \\
\hline & Pres. Joao Goulart & 178,06 & 60,83 & 34,16 & 71,34 & 40,07 & 44,9 & 25,22 & 0,99 & 0,56 \\
\hline & TOTAL & 2038,48 & 373,89 & 18,34 & 1104,45 & 54,18 & 498,98 & 24,48 & 61,16 & 3,00 \\
\hline \multirow{2}{*}{ 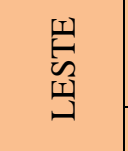 } & Camobi & 2040,29 & 644,97 & 31,61 & 617,57 & 30,27 & 751,04 & 36,81 & 26,71 & 1,31 \\
\hline & TOTAL & 2040,29 & 644,97 & 31,61 & 617,57 & 30,27 & 751,04 & 36,81 & 26,71 & 1,31 \\
\hline \multirow{5}{*}{ 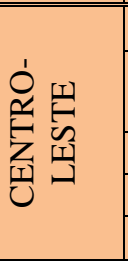 } & Cerrito & 462,13 & 75,16 & 16,26 & 260,32 & 56,33 & 126,24 & 27,32 & 0,41 & 0,09 \\
\hline & $\begin{array}{c}\text { Diácono João Luiz } \\
\text { Pozzobon }\end{array}$ & 775,23 & 125,18 & 16,15 & 196,14 & 25,30 & 449,03 & 57,92 & 4,88 & 0,63 \\
\hline & Pé-de-Plátano & 411,60 & 80,25 & 19,50 & 105,78 & 25,70 & 222,17 & 53,98 & 3,4 & 0,83 \\
\hline & São José & 466 & 123,99 & 26,61 & 134,99 & 28,97 & 203,78 & 43,73 & 3,24 & 0,70 \\
\hline & TOTAL & 2114,96 & 404,58 & 19,13 & 697,23 & 32,97 & 1001,22 & 47,34 & 11,93 & 0,56 \\
\hline \multirow{5}{*}{$\stackrel{5}{\omega}$} & Dom Antônio Reis & 62,42 & 37,64 & 60,30 & 14,00 & 22,43 & 10,61 & 17,00 & 0,17 & 0,27 \\
\hline & Lorenzi & 484,73 & 139,44 & 28,77 & 130,2 & 26,86 & 207,84 & 42,88 & 7,25 & 1,50 \\
\hline & Tomazetti & 585,44 & 140,9 & 24,07 & 160,14 & 27,35 & 275,19 & 47,01 & 9,21 & 1,57 \\
\hline & Urlândia & 273,88 & 116,18 & 42,42 & 76,77 & 28,03 & 79,62 & 29,07 & 1,31 & 0,48 \\
\hline & TOTAL & 1406,47 & 434,16 & 30,87 & 381,11 & 27,10 & 573,26 & 40,76 & 17,94 & 1,28 \\
\hline \multirow{4}{*}{ 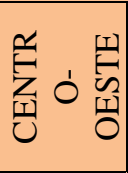 } & "Duque de Caxias & 65,8 & 45,14 & 688,60 & 12,02 & 18,27 & 8,34 & 12,67 & 0,3 & 0,46 \\
\hline & Noal & 124 & 81,13 & 65,43 & 23,63 & 19,06 & 18,83 & 15,19 & 0,41 & 0,33 \\
\hline & Passo D’Areia & 265,37 & 126,65 & 47,73 & 58,83 & 22,17 & 76,48 & 28,82 & 3,41 & 1,28 \\
\hline & Patronato & 118,32 & 72,73 & 61,47 & 23,44 & 19,81 & 21,91 & 18,52 & 0,24 & 0,20 \\
\hline
\end{tabular}

Daniel Borini Aves e Adriano Severo Figueiró 


\begin{tabular}{|c|c|c|c|c|c|c|c|c|c|c|}
\hline & Uglione & 67,79 & 35,62 & 52,54 & 17,48 & 25,79 & 14,52 & 21,42 & 0,17 & 0,25 \\
\hline & TOTAL & 641,28 & 361,27 & 56,34 & 135,4 & 21,11 & 140,08 & 21,84 & 4,53 & 0,71 \\
\hline \multirow{9}{*}{$\begin{array}{l}\underset{1}{E} \\
\infty \\
\text { [I } \\
0\end{array}$} & "Agroindustrial & 651,18 & 118,99 & 18,27 & 136,01 & 20,89 & 389,21 & 59,77 & 6,97 & 1,07 \\
\hline & Boi Morto & 583,82 & 61,45 & 10,53 & 171,18 & 29,32 & 346,9 & 59,42 & 4,29 & 0,73 \\
\hline & $\begin{array}{c}\text { Juscelino } \\
\text { Kubitschek }\end{array}$ & 247,98 & 157,4 & 63,47 & 46,65 & 18,81 & 43,15 & 17,40 & 0,78 & 0,31 \\
\hline & Nova Santa Marta & 207,4 & 109,94 & 53,01 & 43,04 & 20,75 & 53,64 & 25,86 & 0,78 & 0,38 \\
\hline & Pinheiro Machado & 356,34 & 167,99 & 47,14 & 69,98 & 19,64 & 118,02 & 33,12 & 0,35 & 0,10 \\
\hline & Renascença & 141,86 & 28,38 & 20,01 & 38,92 & 27,44 & 73,89 & 52,09 & 0,67 & 0,47 \\
\hline & São João & 85,17 & 40,41 & 47,45 & 17,44 & 20,48 & 27,09 & 31,81 & 0,23 & 0,27 \\
\hline & Tancredo Neves & 340,41 & 125,12 & 36,76 & 67,08 & 19,71 & 144,2 & 42,36 & 4,01 & 1,18 \\
\hline & TOTAL & 2614,16 & 809,68 & 30,97 & 590,3 & 22,58 & 1196,1 & 45,75 & 18,08 & 0,69 \\
\hline TODAS & TOTAL & 12945,8 & 3912,82 & 30,22 & 4259,24 & 32,90 & 4625,21 & 35,73 & 148,53 & 1,15 \\
\hline
\end{tabular}

Table 2. Land use and cover per units of districts in urban area of Santa Maria (2011).

RAs=Regiões Administrativas; EC= Espaços Construídos; CVA= Cobertura Vegetal Arbórea; CVHA= Cobertura Vegetal Herbácea ou Arbustiva; $\mathbf{R D}=$ Rede de Drenagem.

*Para cada classe indica-se a área ocupada (ha) e a proporção de área ocupada (\%) em relação à área total dos bairros.

Na RA Centro-Oeste se registrou as maiores porcentagens de crescimento do adensamento de edificações, sendo que a classe de espaços construídos apresentou 26,45\% de aumento, que avançaram sobre as áreas de vegetação, que perderam cerca de $13 \%$ de cobertura vegetal arbórea e outros 13\% de cobertura vegetal herbácea e arbustiva. Registre-se que boa parte desta perda de cobertura arbórea refere-se à supressão ilegal de mata-galeria, o que remete a implicações que vão para muito além da funcionalidade biótica do sistema, envolvendo também uma mudança profunda na sua funcionalidade hidrológica.

Na RA Oeste, o avanço dessas áreas se refletiu mais na perda da cobertura vegetal de porte herbáceo e arbustivo do que na de porte arbóreo, já que os 18,08\% de avanço dos espaços construídos esteve relacionado à perda de $14 \%$ de vegetação de porte herbáceo e arbustivo.

Na RA Sul, que apresentou avanço dos espaços construídos de cerca de 15\% em relação a 1980, tem-se o destaque para os bairros Dom Antônio Reis e Urlândia, que tiveram o adensamento de edificações crescendo, respectivamente, 39,76\% e $20,97 \%$.

As RAs Centro-Leste e Leste apresentaram quadros semelhantes, com um avanço das áreas edificadas não tão intenso num comparativo com as porcentagens de 1980 (12,37\% na RA Leste e 9,69\% na RA CentroLeste), mas que já apontam para a tendência de adensamento no bairro Camobi neste vetor leste da cidade. A RA Centro-Leste apresentou uma perda de cerca de 3\% de cobertura vegetal arbórea e outros 6\% de cobertura vegetal herbácea e arbustiva. Na RA Leste, a perda de cobertura vegetal herbácea e arbustiva também foi mais significativa, cerca de $11 \%$, somados a outro $1 \%$ de perda de cobertura vegetal arbórea.

Focando a discussão na dinâmica de cobertura vegetal entre as datas mapeadas, se observa na Tabela 3 as perdas de vegetação por bairros nos últimos trinta e um anos. Considerando as limitações impostas pela distinção dos produtos base das classificações, define-se uma margem de erro de 3,5\% com fins de comparação entre os períodos analisados. 
Destaca-se em um primeiro momento que na variação em todos os bairros entre as datas analisadas, tanto na coluna de cobertura vegetal arbórea quanto na cobertura vegetal total, apresenta-se um panorama de perda de espaços verdes. De forma geral, observa-se uma perda de $12,38 \%$ da cobertura vegetal total da cidade nesses 31 anos, sendo contabilizadas perdas de 4,6\% apenas para a vegetação arbórea da cidade. Em âmbitos comparativos, ressalta-se que as porcentagens de perda encontradas para a área urbana de Santa Maria se assemelham aos valores encontrados para outras cidades brasileiras em períodos similares e submetidas a ritmos semelhantes de crescimento. Em Curitiba, entre 1986 e 2004, Vieira e Biondi (2008) identificaram perdas de 9\% de cobertura vegetal (de 39\% em 1986 para 30\% em 2004). Já para Salvador, entre 1995 (43,75\%) e 2007 (33,59\%), Afonso et al. (2010) registraram $10,16 \%$ de perdas de cobertura vegetal.

As RAs Centro-Oeste e Centro Urbano (Figura 4) foram as que registraram maiores perdas em ambas as classes. No Centro Urbano, os bairros perderam cerca de $20 \%$ de cobertura vegetal total, sendo aproximadamente $15 \%$ de perdas de cobertura vegetal arbórea. A RA Centro-Oeste registrou perda de cobertura vegetal total ainda maior (26,45\%), estando inseridas dentro dessa porcentagem a perda de cerca de $13 \%$ de cobertura vegetal arbórea. Nesta última região, um destaque de perda de vegetação foi para o bairro Noal, que apresentava 82,50\% de vegetação em 1966 (ALVES, 2012), passou para 68,08\% em 1980 e, finalmente, para $34,25 \%$ de cobertura vegetal em 2011, revelando uma perda significativa de estrutura ecológica nas últimas décadas.

As RAs Nordeste e Norte foram as que apresentaram a menor porcentagem de perda de cobertura vegetal entre 1980 e 2011. A RA Norte apresentou perda de 5,67\% de cobertura vegetal total, enquanto a RA Nordeste apresentou perda de 2,96\%.

Em relação à perda de cobertura vegetal exclusivamente arbórea, o quadro foi semelhante, com perda de 2,63\% na RA Norte e 3,58\% na RA Nordeste. Mesmo sendo o quadro geral das regiões de perda menor em relação aos demais, alguns bairros, como o Divina Providência (Figura 5), apresentou um avanço significativo dos espaços construídos.

Tabela 3. Variação da porcentagem de cobertura vegetal entre 1980 e 2011. 


\begin{tabular}{|c|c|c|c|c|c|c|c|}
\hline \multirow{3}{*}{ RAs } & \multirow{3}{*}{ Bairros } & \multicolumn{6}{|c|}{ Cobertura vegetal e sua variação (\%) } \\
\hline & & \multicolumn{2}{|c|}{1980} & \multicolumn{4}{|c|}{2011} \\
\hline & & CVA & CVT & CVA & $\overline{\mathbf{V}}$ & CVT & $\overline{\mathbf{V}}$ \\
\hline \multirow{8}{*}{ 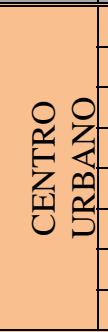 } & Bonfim & 24,94 & 31,65 & 10,01 & $-14,93$ & 13,44 & $-18,21$ \\
\hline & Centro & 24,52 & 30,88 & 10,02 & $-14,5$ & 13,64 & $-17,24$ \\
\hline & Nonoai & 37,45 & 49,3 & 21,69 & $-15,76$ & 32,16 & $-17,14$ \\
\hline & Nossa Sra. de Fátima & 32,93 & 40,98 & 15,31 & $-17,62$ & 21,98 & -19 \\
\hline & Nossa Sra. de Lourdes & 40,85 & 59,58 & 24,88 & $-15,97$ & 38,12 & $-21,46$ \\
\hline & Nossa Sra. Medianeira & 33,56 & 68,46 & 19,01 & $-14,55$ & 38,31 & $-30,15$ \\
\hline & Nossa Sra. do Rosário & 25,16 & 34 & 15,23 & $-9,93$ & 22,34 & $-11,66$ \\
\hline & TOTAL & 31,64 & 47,11 & 16,84 & $-14,8$ & 26,76 & $-20,35$ \\
\hline \multirow{7}{*}{$\begin{array}{l}\text { 工工I } \\
\text { م્ન } \\
0 \\
z\end{array}$} & Carolina & 33,86 & 45,14 & 24,68 & $-9,18$ & 35,36 & $-9,78$ \\
\hline & Caturrita & 33,98 & 93,04 & 33,13 & $-0,85$ & 87,18 & $-5,86$ \\
\hline & Chácara das Flores & 60,29 & 83,22 & 52,9 & $-7,39$ & 79,75 & $-3,47$ \\
\hline & Divina Providência & 27,25 & 73,44 & 19,8 & $-7,45$ & 48,84 & $-24,6$ \\
\hline & $\begin{array}{c}\text { Nossa Sra. do } \\
\text { Perpétuo Socorro }\end{array}$ & 66,74 & 83,7 & 66,47 & $-0,27$ & 82,75 & $-0,95$ \\
\hline & Salgado Filho & 22,27 & 46,58 & 19,53 & $-2,74$ & 29,85 & $-16,73$ \\
\hline & TOTAL & 49,19 & 82,2 & 46,56 & $-2,63$ & 76,53 & $-5,67$ \\
\hline \multirow{7}{*}{ 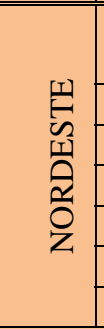 } & $\begin{array}{c}\text { Campestre Menino } \\
\text { Deus }\end{array}$ & 63,13 & 91,6 & 59,68 & $-3,45$ & 89,62 & $-1,98$ \\
\hline & Itararé & 45,87 & 68,92 & 45,48 & $-0,39$ & 64,8 & $-4,12$ \\
\hline & $\mathrm{Km} 3$ & 69,32 & 84,14 & 65,29 & $-4,03$ & 83,66 & $-0,48$ \\
\hline & Menino Jesus & 32,39 & 44,02 & 17,99 & $-14,4$ & 24,25 & $-19,77$ \\
\hline & Nossa Sra. das Dores & 28,82 & 44,54 & 21,83 & $-6,99$ & 32,38 & $-12,16$ \\
\hline & Pres. Joao Goulart & 41,78 & 66,69 & 40,07 & $-1,71$ & 65,29 & $-1,4$ \\
\hline & TOTAL & 57,76 & 81,62 & 54,18 & $-3,58$ & 78,66 & $-2,96$ \\
\hline \multirow{2}{*}{ 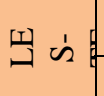 } & Camobi & 31,02 & 79,45 & 30,27 & $-0,75$ & 67,08 & $-12,37$ \\
\hline & TOTAL & 31,02 & 79,45 & 30,27 & $-0,75$ & 67,08 & $-12,37$ \\
\hline \multirow{5}{*}{ 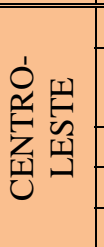 } & Cerrito & 56,59 & 86,2 & 56,33 & $-0,26$ & 83,65 & $-2,55$ \\
\hline & $\begin{array}{l}\text { Diácono João Luiz } \\
\text { Pozzobon }\end{array}$ & 29,14 & 96,57 & 25,3 & $-3,84$ & 83,22 & $-13,35$ \\
\hline & Pé-de-Plátano & 28,02 & 88,18 & 25,7 & $-2,32$ & 79,68 & $-8,5$ \\
\hline & São José & 34,03 & 84,43 & 28,97 & $-5,06$ & 72,7 & $-11,73$ \\
\hline & TOTAL & 36 & 90 & 32,97 & $-3,03$ & 80,31 & $-9,69$ \\
\hline \multirow{5}{*}{ S } & Dom Antônio Reis & 24,53 & 79,19 & 22,43 & $-2,1$ & 39,43 & $-39,76$ \\
\hline & Lorenzi & 33,71 & 85,42 & 26,86 & $-6,85$ & 69,74 & $-15,68$ \\
\hline & Tomazetti & 40,96 & 83,78 & 27,35 & $-13,61$ & 74,36 & $-9,42$ \\
\hline & Urlândia & 28,57 & 78,07 & 28,03 & $-0,54$ & 57,1 & $-20,97$ \\
\hline & TOTAL & 35,32 & 83,03 & 27,1 & $-8,22$ & 67,86 & $-15,17$ \\
\hline \multirow{6}{*}{ 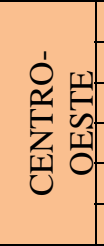 } & "Duque de Caxias & 23,57 & 55,42 & 18,27 & $-5,3$ & 30,94 & $-24,48$ \\
\hline & Noal & 36,35 & 68,08 & 19,06 & $-17,29$ & 34,25 & $-33,83$ \\
\hline & Passo D’Areia & 36,15 & 72,61 & 22,17 & $-13,98$ & 50,99 & $-21,62$ \\
\hline & Patronato & 37,76 & 68,24 & 19,81 & $-17,95$ & 38,33 & $-29,91$ \\
\hline & Uglione & 28,63 & 74,83 & 25,79 & $-2,84$ & 47,21 & $-27,62$ \\
\hline & TOTAL & 34,4 & 69,4 & 21,11 & $-13,29$ & 42,95 & $-26,45$ \\
\hline \multirow{9}{*}{ 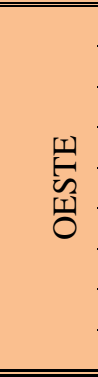 } & Agroindustrial & 21,71 & 91,96 & 20,89 & $-0,82$ & 80,66 & $-11,3$ \\
\hline & Boi Morto & 29,66 & 91,62 & 29,32 & $-0,34$ & 88,74 & $-2,88$ \\
\hline & Juscelino Kubitschek & 24,77 & 54,09 & 18,81 & $-5,96$ & 36,21 & $-17,88$ \\
\hline & Nova Santa Marta & 22,28 & 86,39 & 20,75 & $-1,53$ & 46,61 & $-39,78$ \\
\hline & Pinheiro Machado & 21,65 & 82,59 & 19,64 & $-2,01$ & 52,76 & $-29,83$ \\
\hline & Renascença & 30,88 & 87,09 & 27,44 & $-3,44$ & 79,53 & $-7,56$ \\
\hline & São João & 20,84 & 82 & 20,48 & $-0,36$ & 52,29 & $-29,71$ \\
\hline & Tancredo Neves & 34,84 & 93,06 & 19,71 & $-15,13$ & 62,07 & $-30,99$ \\
\hline & TOTAL & 25,99 & 86,13 & 22,58 & $-3,41$ & 68,33 & $-17,8$ \\
\hline TOD & TOTAL & 37,5 & 81,01 & 32,9 & $-4,6$ & 68,63 & $-12,38$ \\
\hline
\end{tabular}

VARIAÇÃO DA ESTRUTURA HORIZONTAL DE COBERTURA... 
RAs=Regiões Administrativas; CVA= Cobertura Vegetal Arbórea; CVT= Cobertura Vegetal Total; V=Variação em relação à data anterior.

Figura 4. Variação da cobertura vegetal nas RAs Centro Urbano e Centro-Oeste.

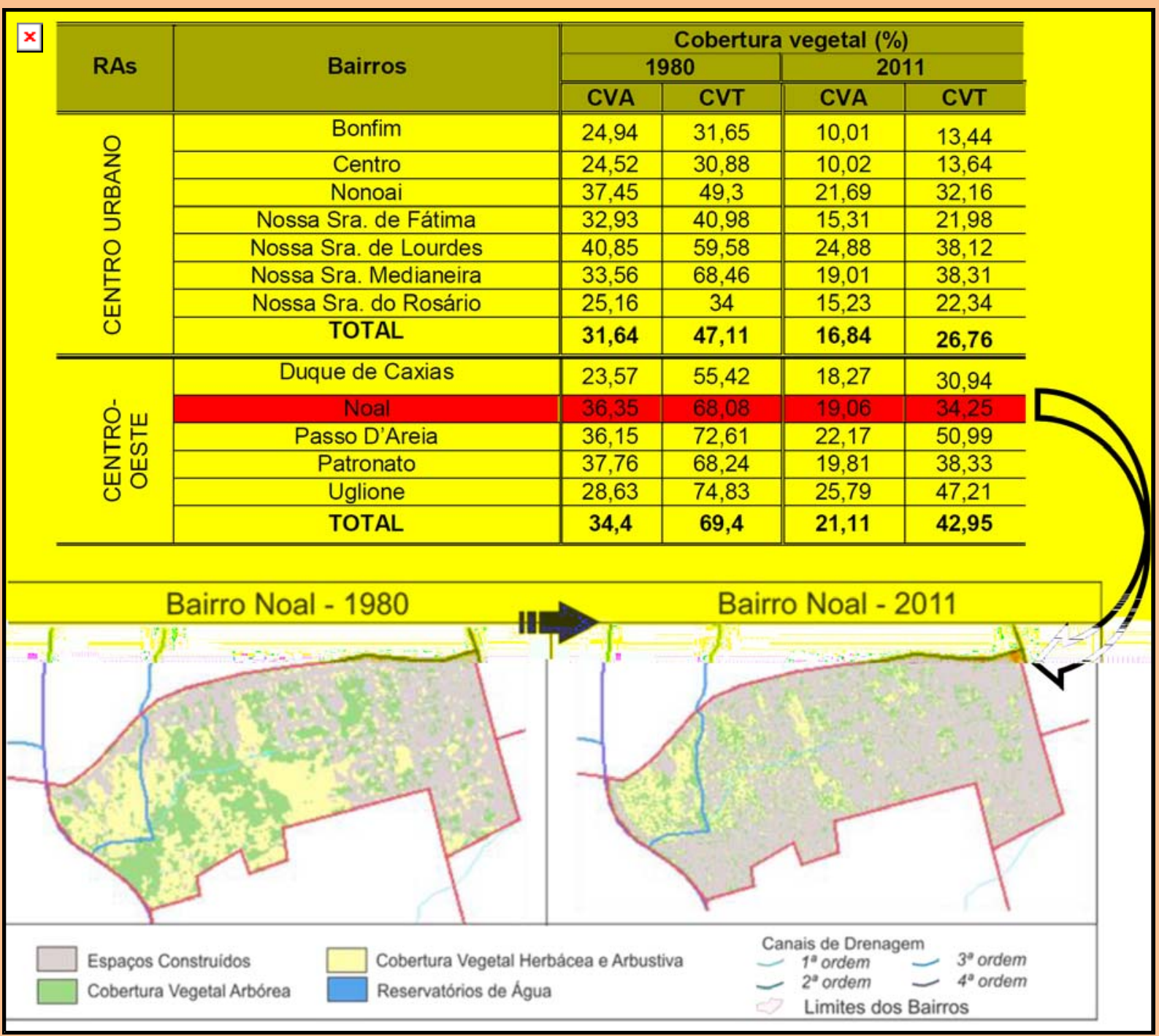

Fonte: elaborado pelos autores. 
Figura 5. Variação da cobertura vegetal nas RAs Nordeste e Norte.

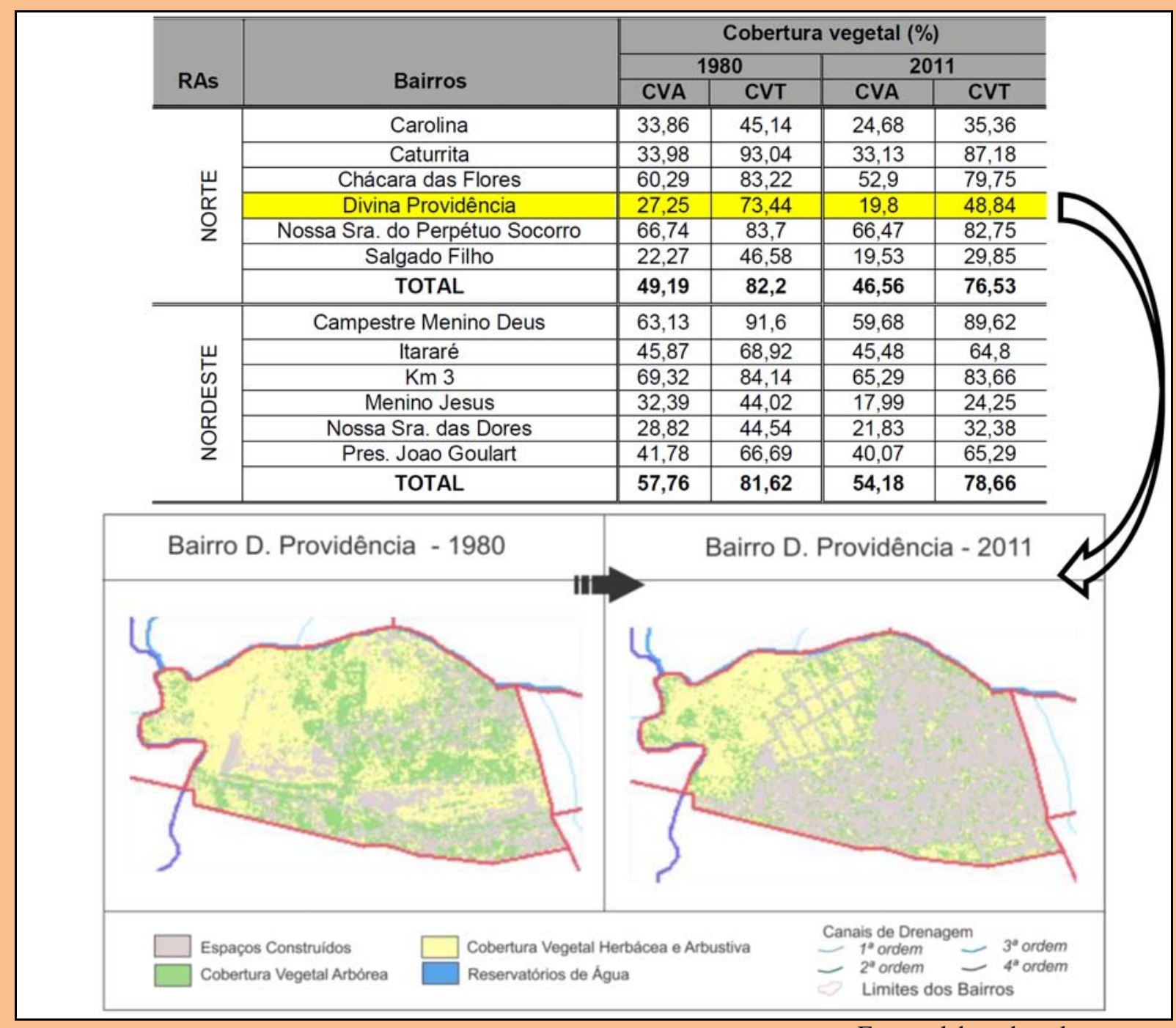

Fonte: elaborado pelos autores

As RAs Leste e Centro-Leste (Figura 6) apresentam quadros semelhantes, onde as perdas de cobertura vegetal total foram de $12,37 \%$ e $9,69 \%$, respectivamente, sendo que na RA Centro-Leste a diminuição da cobertura vegetal arbórea foi um tanto inferior do que na RA Leste, com valores respectivos de 3,03\% e 0,75\%. Os bairros Camobi, Diácono João Luiz Pozzobon e São José são os que registraram as maiores perdas de cobertura vegetal total, superiores a $10 \%$, enquanto o bairro Cerrito é o que registra a menor porcentagem de perda de cobertura vegetal, com aproximadamente $3 \%$. 
Figura 6. Variação da cobertura vegetal nas RAs Leste e Centro-Leste.

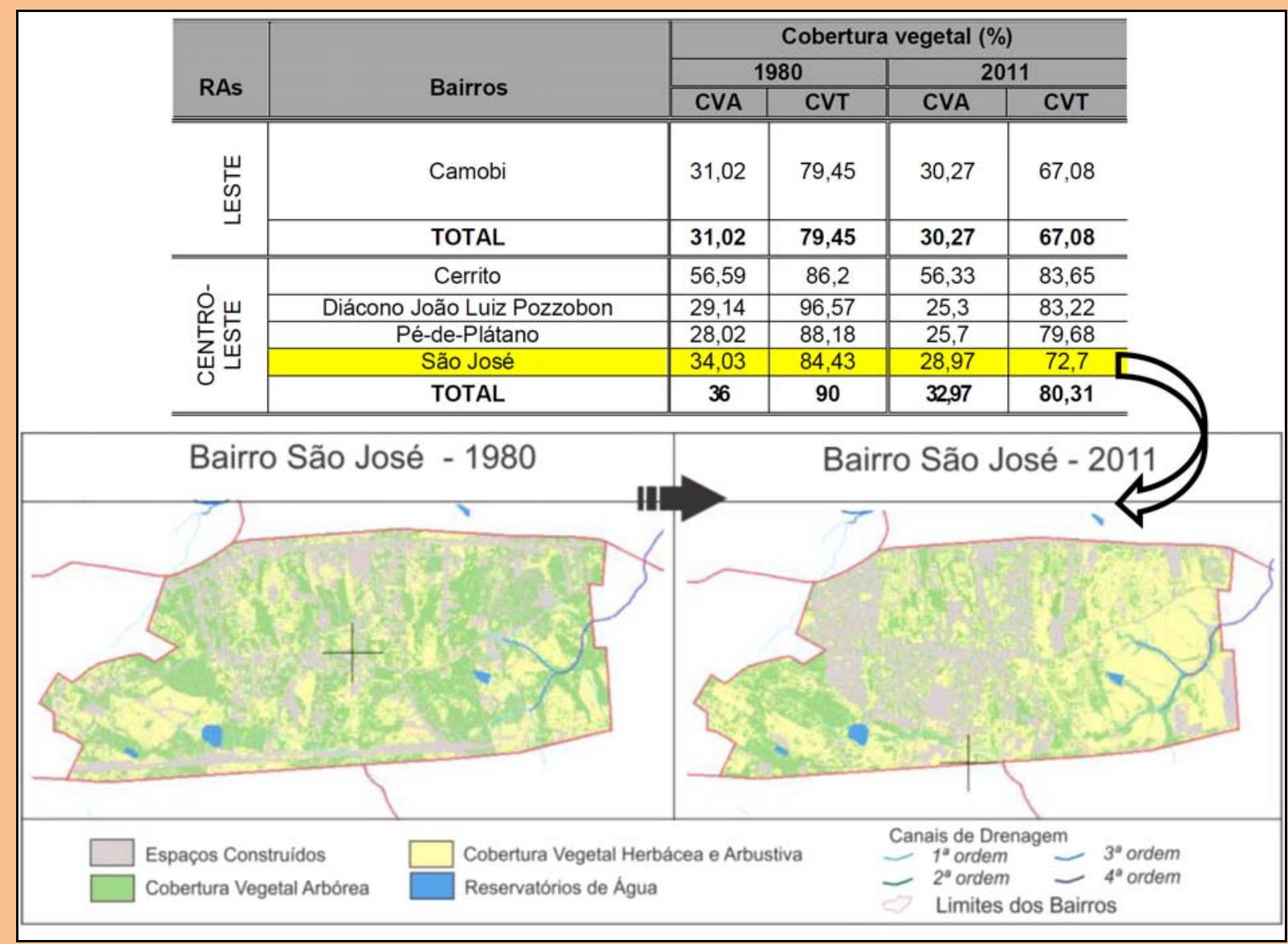

Fonte: elaborado pelos autores

As RAs Oeste e Sul (Figura 7) apresentam também condições de similaridade. As duas apresentam um decréscimo de cobertura vegetal de valores aproximados, com perda de 17,8\% na Oeste e 15,17\% na Sul. As duas regiões também apresentam bairros mais próximos da área central que tiveram suas porcentagens de cobertura vegetal bastante diminuídos.
Na RA Oeste, destaque para os bairros Tancredo Neves e Nova Santa Marta, que totalizaram perdas 30,99\% e $39,78 \%$ de cobertura vegetal total, enquanto os bairros Dom Antônio Reis e Urlândia, na RA Sul, apresentaram diminuição da cobertura vegetal de $39,76 \%$ e $20,97 \%$, respectivamente. 
Figura 7. Variação da cobertura vegetal nas RAs Oeste e Sul.

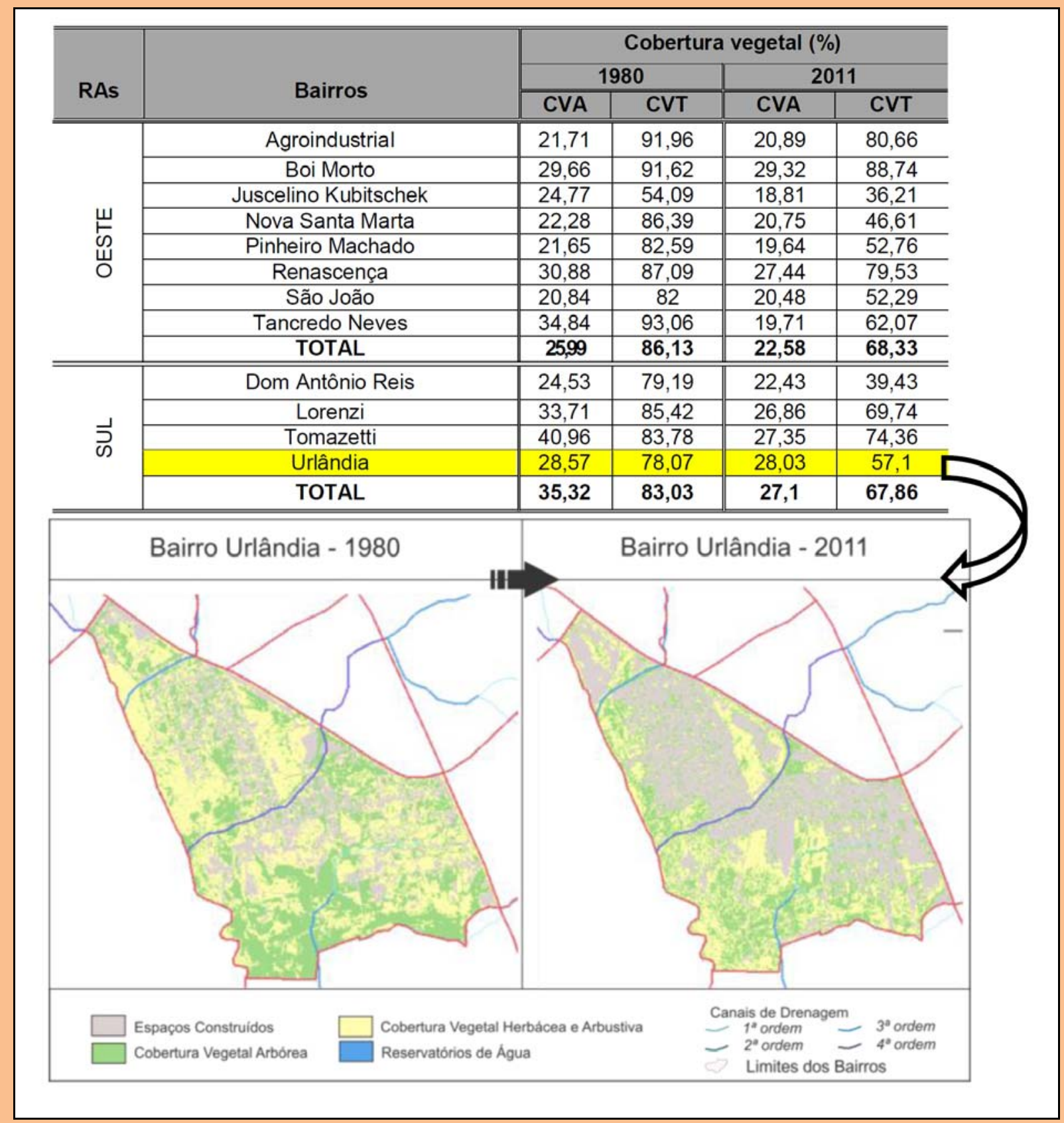

Fonte: elaborado pelos autores

Em uma classificação dos bairros de acordo com suas porcentagens de variação de cobertura vegetal total no período analisado (Figura 8), verificam-se onde as perdas ocorreram com maior intensidade por setores da cidade. 
Figura 8. Classificação da perda de cobertura vegetal (1980-2011) por unidades de bairros.

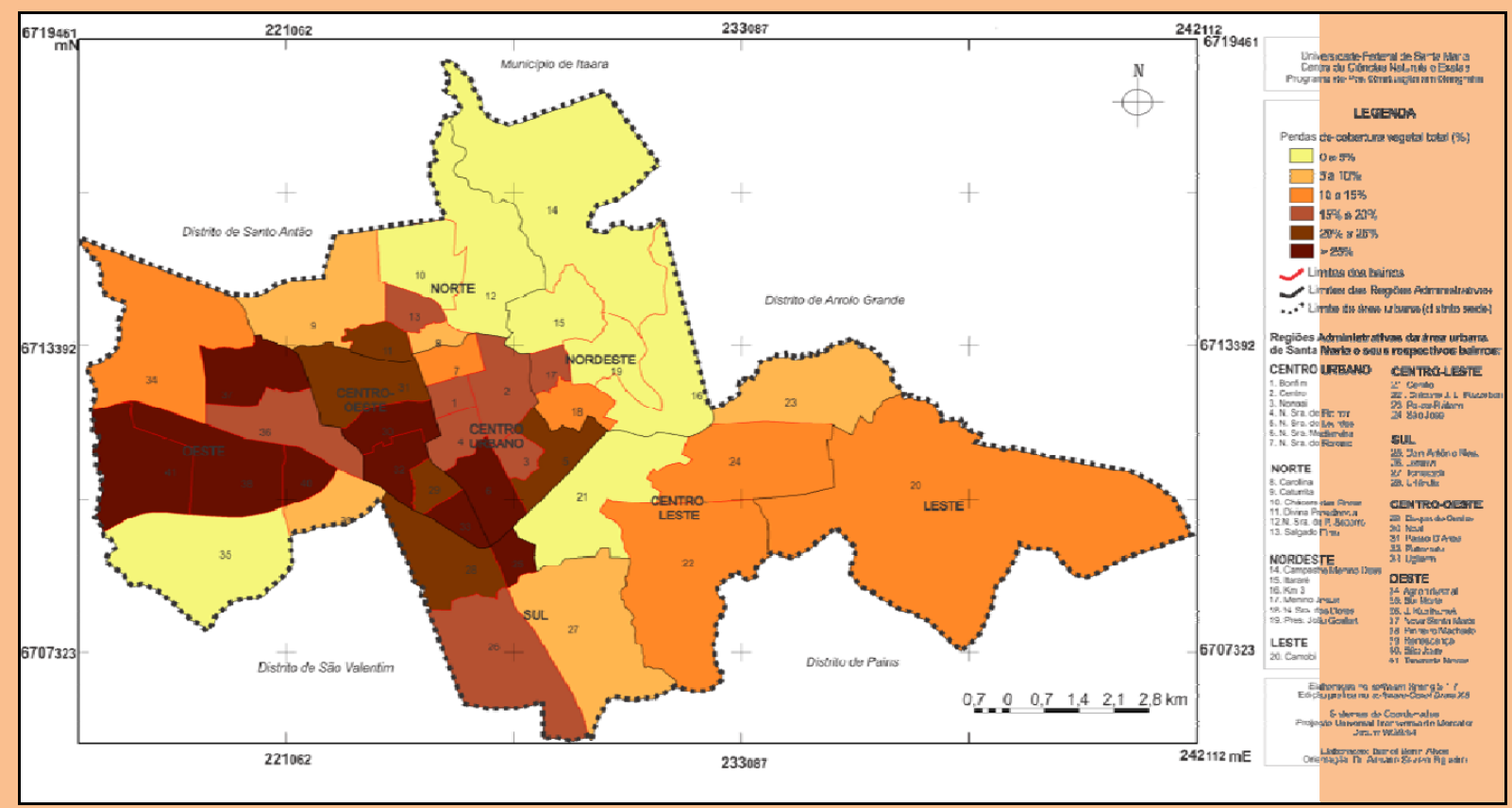

Fonte: elaborado pelos autores

Os bairros que apresentaram as menores perdas de porcentagem de cobertura vegetal - incluídos na classe de perda de 0 a $5 \%$ - se referem justamente aos que apresentam barreiras geomorfológicas de adensamento (morros testemunhos e rebordo do planalto), tais como os bairros Cerrito, Chácara das Flores e Itararé. O bairro de exceção a essa lógica e incluído nessa classe, é o Boi Morto, na RA Oeste, em que a limitação da expansão urbana é dada, em grande parte, pela presença de grandes áreas de treinamento militar do Exército Brasileiro.

Por outro lado, ao contrário do que se poderia prever, os bairros da RA Centro Urbano não são os que apresentaram a pior dinâmica de retração no período 1980-2011. Mas isso, obviamente, não se deve ao fato desta região estar em melhores condições de conservação da cobertura vegetal do que as demais, e sim que esta Região já se aproxima bastante de um deserto biológico, ou seja, seus patamares de retração têm pouco a evoluir, especialmente por se tratar de uma área de ocupação já quase que totalmente consolidada. Mesmo assim, se pode destacar os bairros N. Sra. Medianeira e N. Sra. de Lourdes, incluídos nas duas classes de maiores contabilização de perda de cobertura vegetal nas últimas décadas.

Já as RAs Centro-Oeste e Oeste são as que possuem o maior número de bairros incluídos na classe de maiores porcentagens de perdas, o que demonstra claramente onde esteve localizado o principal vetor de adensamento de áreas edificadas da cidade nestas últimas décadas. Destacam-se com maiores porcentagens de perdas na RA Centro-Oeste os bairros Noal, Patronato e Uglione, enquanto que na RA Oeste destacam-se os bairros Nova Santa Marta, Tancredo Neves, Pinheiro Machado e São João. 
Os bairros das RAs Leste e Centro-Leste foram incluídos em sua maioria na classe de perdas entre 10 e $15 \%$, o que denota que essa área vem perdendo gradualmente quantidades significativas de cobertura vegetal. Em uma análise prospectiva, indica-se que possivelmente serão os bairros das RAs Centro-Leste, Leste e Sul que deverão apresentar as principais mudanças de classe para as próximas décadas, com o avanço dos espaços construídos.

\section{Possíveis quadros de ação frente ao panorama de perda de cobertura vegetal identificado}

Diante desse quadro de supressão gradual de cobertura vegetal que a paisagem urbana de Santa Maria tem vivido nas últimas décadas, acredita-se que nos bairros mais adensados, como o exemplo dos situados nas RAs Centro Urbano e CentroOeste, uma melhoria da estrutura geoecológica poderia ser conseguida com a garantia de uso de algumas áreas livres ainda existentes para a criação de parques urbanos que, para além dos ganhos ecológicos diretos, podem também estar associadas ao lazer dos habitantes citadinos. Outra sugestão que merece ser mais bem discutida refere-se a possíveis incentivos do poder público municipal à adoção de telhados verdes, principalmente nas zonas mais adensadas com presença de edifícios, onde a liberação de áreas para a reintrodução da vegetação parece ser atualmente inviável.

Nos espaços onde o adensamento urbano ainda não atingiu grandes proporções, como o exemplo dos bairros na RA Leste, é possível incentivar a arborização dos pátios, buscando integrar jardins de residências e ampliar e otimizar a distribuição do verde, ao mesmo tempo que se deve evitar a construção de residenciais com alta densidade de edificações. No bairro Camobi, identificado como uma das principais áreas de expansão dos espaços construídos nas últimas décadas, observase a implantação de uma grande quantidade de condomínios com altos índices de área edificada. Considera-se extremamente relevante que se estude atentamente os limites e possibilidades de restrição ao adensamento dessas áreas, visando o não comprometimento de determinadas funcionalidades ambientais.

Sugere-se também que se dê especial atenção às áreas nas margens e nos arredores das nascentes dos rios urbanos. Devem-se analisar as áreas de preservação permanente associadas aos recursos hídricos inseridos na malha urbana, identificando os locais que necessitam da recuperação das Áreas de Preservação Permanente (APPs). Alguns exemplos podem ser citados, como é o caso de grande parte das margens na extensão do Arroio Cancela, que estão inseridas nas proximidades de áreas altamente adensadas, e também nas margens de alguns tributários do Arroio Cadena nos bairros Passo D’Areia e Noal, que se encontram muito deterioradas.

Nas áreas de morros testemunhos, situadas essencialmente em áreas das RAs Centro-Leste, Norte e Nordeste, é necessário continuar evitando que as malhas de extensão viária e de edificações se expandam por esse vetor. A criação de unidades de conservação, como discutido no trabalho de Nascimento e Foleto (2010), pode contribuir plenamente com a contenção dessa expansão, e deve ter a Reserva da Biosfera da Mata Atlântica como referência na instituição e zoneamento da Área de Proteção Ambiental do Vacacaí-Mirim/RS. Onde ainda se observa uma boa matriz de cobertura vegetal em meio a uma área de pouco avanço das áreas edificadas, deve-se procurar manter a condição de conservação natural, evitando maiores adensamentos. A criação de parques também se demonstra como uma 
boa estratégia de manutenção desses atributos, onde se salienta que a sua implementação deve considerar o conceito de parque difundido no Sistema Nacional de Unidades de Conservação (SNUC) (BRASIL, 2000).

Nas áreas mais periféricas de pouco avanço de edificações, que se acredita serem estratégicas para a expansão urbana nas próximas décadas, sugere-se que as alternativas de manutenção da cobertura vegetal desde já devem ser pauta de discussão, para que as possibilidades de expansão possam ser realizadas de forma mais harmoniosa com os atributos e processos naturais, especialmente nas áreas mais baixas e de menor declividade, que deverão continuar a servir como amortecedores da água escoada pela chuva em episódios de precipitação pluviométrica mais intensa.

É importante ressaltar que a implantação dessas áreas verdes não deve ser descontextualizada de ações de educação ambiental que possam sensibilizar a população para a importância de manutenção desses atributos naturais dentro da cidade.

\section{CONCLUSÕES}

A dinâmica de uso e cobertura da terra dos últimos 31 anos na área urbana de Santa Maria revela que o crescimento das áreas edificadas tem refletido em um panorama de perda de cobertura vegetal nos mais distintos bairros da cidade.

Diante desse panorama, espera-se que os resultados aqui obtidos e discutidos, em torno da relevância do verde urbano e da sua tendência de supressão nas últimas décadas, possam servir também como propulsores para que o conjunto de políticas do poder público municipal possa caminhar no sentido da adequação de ações que considerem os atributos naturais da cidade de forma mais contextualizada e integrada.
Certo de que a inserção de cobertura vegetal pode contribuir com a gestão ambiental urbana das cidades, é importante destacar que aqui não se defende que as políticas ambientais urbanas devam ser reduzidas apenas a esse tipo de ação. É extremamente importante que sejam mais bem considerados demais atributos como a proteção e controle de qualidade dos recursos hídricos, a manutenção e limitações de uso do solo de acordo com as condições geomorfológicas, entre outros, para que se possa caminhar em direção a melhores condições de qualidade ambiental e de vida em áreas urbanas.

\section{AGRADECIMENTOS}

Os autores agradecem ao Conselho Nacional de Desenvolvimento Científico e Tecnológico (CNPq), pela bolsa de mestrado $\mathrm{CNPq}$ concedida ao primeiro autor para o desenvolvimento da pesquisa que subsidiou a elaboração desse trabalho.

\section{REFERÊNCIAS BIBLIOGRÁFICAS}

AFONSO, L. D.; SOUSA, A. N.; MONTEIRO, S. S. A dinâmica de cobertura vegetal de Salvador - BA (1995 a 2007$)$ : entre o fetiche e a degradação. Revista VeraCidade, ano V, n.6, dez. 2010. 
ALBERTI, M. Urban patterns and environmental performance: what do we know? Journal of Planning Education and Research. 19, p. 151-163, 1999.

BORGES, C. A. R.; MARIM, G. C.; RODRIGUES, J. E. C. Análise da cobertura vegetal como indicador da qualidade ambiental em áreas urbanas: Um estudo de caso do bairro da Pedreira - Belém (PA). In: SEMINÁRIO LATINO AMERICANO DE GEOGRAFIA FÍSICA, VI; SEMINÁRIO IBERO AMERICANO DE GEOGRAFIA FÍSICA, II., 2010. Universidade de Coimbra. Anais... Coimbra, Portugal, 2010.

BRASIL. Lei 9.985, de 18 de julho de 2000. Lei do Sistema Nacional de Unidades de Conservação da Natureza. Diário Oficial da República Federativa do Brasil, Brasília, DF, 18 de julho de 2000. Disponível em: $<$ http://www.planalto.gov.br/ccivil_03/leis/19985.htm>. Acesso em 23 de out. de 2011.

CAVALHEIRO, F. Urbanização e alterações ambientais. In: SANTOS, D. G.; NUCCI, J. C. (org.). Paisagens Geográficas: Um tributo a Felisberto Cavalheiro. Campo Mourão: Ed. da FACILCAM, 2009.

COSTA, J. A.; SILVA FILHO, D. F.; POLIZEL, J. L. Uso de imagens de alta resolução para avaliação de áreas verdes na cidade de São Paulo, Brasil. REVSBAU, Piracicaba - SP, v.7, n.1, p.159-181, 2012.

CPRM. Companhia de Pesquisas em Recursos Minerais. Mapa de geodiversidade do Rio Grande do Sul. SGMTM, CRPM, Brasília, 2010. Disponível em: < http://www.cprm.gov.br/publique/media/geodiversidade_rio grande_sul.pdf>. Acesso em 11 de fev. de 2014.

DIAS, G. F. Elementos de ecologia urbana e sua estrutura ecossistêmica. Brasília: IBAMA, 1997.

IBGE. Instituto Brasileiro de Geografia e Estatística. Censo demográfico 2010. Rio de Janeiro, 2010.

IBGE. Instituto Brasileiro de Geografia e Estatística. Manual técnico da vegetação brasileira. In: Manuais Técnicos em Geociências, 2a ed. Rio de Janeiro, 2012. Disponível em: <ttp://geoftp.ibge.gov.br/documentos/recursos_naturais/manuais_tecnicos/manual_tecnico_vegetacao_brasileira. pdf $>$ Acesso em 11 de fev. de 2014.

JIM, C. Y.; CHEN, W. Y. Assessing the ecosystem servisse o fair pollutant removal by urban trees in Guangzou (China). Journal of Environmental Management, 88, p. 665-676, 2008.

LANDIS, J. R.; KOCH, G. G. The measurement of observer agreement for categorical data. Biometrics, v.33, n.1, p.159-174, 1977.

LÖFVENHAFT, K.; BJÖRN, C.; IHSEA M. Biotope patterns in urban areas: A conceptual model integrating biodiversity issues in spatial planning. Landscape and Urban Planning, v. 58, n. 2-4, p. 223-240, 2002.

MAIMAITIYIMING, M.; GHULAM, A.; TIYIP, T.; PLA, F.; LATORRE-CARMONA, P.; HALIK, U.; SAWUT, M.; CAETANO, M. Effect of green space spatial pattern on land surfasse temperature: implications for sustainable urban planning and climate change adaption. Journal of Photogrammetry and Remote Sensing, v. 89, 2014.

NASCIMENTO, D. B.; FOLETO, E. M. A Reserva da Biosfera da Mata Atlântica como referência na instituição e zoneamento da Área de Proteção Ambiental do Vacacaí-Mirim/RS. In: FIGUEIREDO, L. C.; FIGUEIRÓ, A. S. Geografia do Rio Grande do Sul: temas em debate. Santa Maria: Ed. da Universidade Federal de Santa Maria, 2010.

NUCCI, J. C; CAVALHEIRO, F. Cobertura vegetal em áreas urbanas - conceito e método. Geousp, São Paulo, n. 6, p. 29-36, 1999.

NUCCI, J. C. Qualidade ambiental e adensamento urbano: um estudo de ecologia e planejamento da paisagem aplicado ao distrito de Santa Cecília (MSP). $2^{\text {a }}$ ed. Curitiba: O Autor, 2008. 142p. 
PHAM, T.; APPARICIO, P. SÉGUIN, A.; LANDRY, S.; GAGNON, M. Spatial distribution of vegetation in Montreal: Na uneven distribution or environmental inequity? Landscape and Urban Planning, v. 107, n. 3, p.214-224, 2012.

RIBEIRO, S. R. A.; CENTENO, J. A. S. Classificação do uso do solo utilizando redes neurais e o algoritmo MAXVER. In: SIMPÓSIO BRASILEIRO DE SENSORIAMENTO REMOTO, X, 2001. Foz do Iguaçu, Anais... São José dos Campos: INPE, 2001.

ROSS, J. L. S. Geografia do Brasil. São Paulo: EDUSP, 2001.

SHAN, Y.; JINGPING, C.; LIPING, C.; ZHEMIN, S.; XIAODONG, Z.; DAN, W.; WENHUA, W. Effects of vegetation status in urban green spaces on particle removal in a street canyon atmosphere. Acta ecologica sinica, v. 27, n. 11, nov. 2007.

SPIRN, A. W. O jardim de granito: A natureza no desenho da cidade. Tradução de Paulo Renato Mesquita Pellegrino. São Paulo: Editora da USP, 1995. 345p.

TAKANO, T., NAKAMURA, K., WATANABE, M. Urban residential environments and senior citizens' longevity in megacity areas: the importance of walkable green spaces. Journal of Epidemiology Community Health, n. 56, p. 913-918, 2002

TIAN, Y.; JIM, C. Y.; WANG, H. Assessing the landscape and ecological quality of urban green spaces in a compact city. Landscape and Urban Planning, Elsevier GmbH, v.121, p.97-108, jan./2014.

VIEIRA, C. H. S. D.; BIONDI, D. Análise da dinâmica de cobertura vegetal de Curitiba - PR (de 1986 a 2004 ), utilizando imagens Landsat TM. Revista Árvore, Viçosa - MG, v. 32, n.3, p. 479-487, 2008. 